\title{
Nature of the Cathode-Electrolyte Interface in Highly Concentrated Electrolytes Used in Graphite Dual-Ion Batteries
}

\author{
Antonia Kotronia,* Habtom D. Asfaw, Cheuk-Wai Tai, Maria Hahlin, Daniel Brandell, \\ and Kristina Edström
}

Cite This: ACS Appl. Mater. Interfaces 2021, 13, 3867-3880

Read Online

\section{ACCESS | Lلll Metrics \& More | 回 Article Recommendations | st Supporting Information}

ABSTRACT: Dual-ion batteries (DIBs) generally operate beyond $4.7 \mathrm{~V} \mathrm{vs} \mathrm{Li}^{+} / \mathrm{Li}^{0}$ and rely on the intercalation of both cations and anions in graphite electrodes. Major challenges facing the development of DIBs are linked to electrolyte decomposition at the cathode-electrolyte interface (CEI), graphite exfoliation, and corrosion of $\mathrm{Al}$ current collectors. In this work, X-ray photoelectron spectroscopy (XPS) is employed to gain a broad understanding of the nature and dynamics of the CEI built on anionintercalated graphite cycled both in highly concentrated electrolytes (HCEs) of common lithium salts $\left(\mathrm{LiPF}_{6}, \mathrm{LiFSI}\right.$, and LiTFSI) in carbonate solvents and in a typical ionic liquid. Though $\mathrm{Al}$ metal current collectors were adequately stable in all HCEs, the Coulombic efficiency was substantially higher for HCEs based on LiFSI and LiTFSI salts. Specific capacities ranging from 80 to $100 \mathrm{mAh} \mathrm{g}^{-1}$ were achieved with a Coulombic efficiency above $90 \%$ over extended cycling, but cells with $\mathrm{LiPF}_{6}$-based electrolytes were characterized by $<70 \%$ Coulombic efficiency and specific capacities of

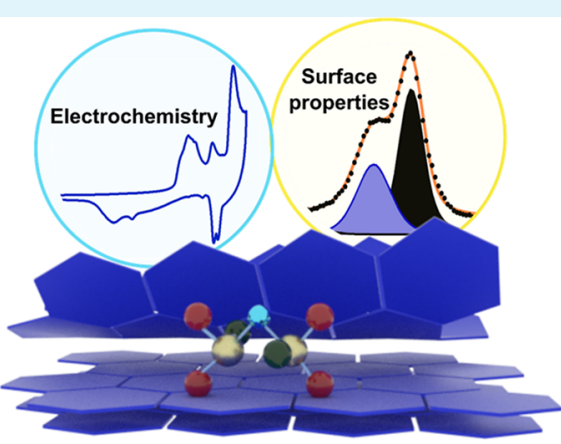

Anion-intercalated graphite merely ca. $60 \mathrm{mAh} \mathrm{g}^{-1}$. The poor performance in $\mathrm{LiPF}_{6}$-containing electrolytes is indicative of the continual buildup of decomposition products at the interface due to oxidation, forming a thick interfacial layer rich in $\mathrm{Li}_{x} \mathrm{PF}_{y}, \mathrm{PO}_{x} \mathrm{~F}_{y}, \mathrm{Li}_{x} \mathrm{PO}_{y} \mathrm{~F}_{z}$, and organic carbonates as evidenced by XPS. In contrast, insights from XPS analyses suggested that anion intercalation and deintercalation processes in the range from 3 to $5.1 \mathrm{~V}$ give rise to scant or extremely thin surface layers on graphite electrodes cycled in LiFSI- and LiTFSI-containing HCEs, even allowing for probing anions intercalated in the near-surface bulk. In addition, ex situ Raman, SEM and TEM characterizations revealed the presence of a thick coating on graphite particles cycled in LiPF 6 -based electrolytes regardless of salt concentration, while hardly any surface film was observed in the case of concentrated LiFSI and LiTFSI electrolytes.

KEYWORDS: graphite, anion intercalation, concentrated electrolyte, cathode-electrolyte interface, photoelectron spectroscopy, battery

\section{INTRODUCTION}

The increasing need to harness renewable energy sources has created a necessity for safe and cost-effective energy storage systems that are suited for large-scale stationary use. Typical examples of battery chemistries employed in such applications include lead-acid, nickel-cadmium, nickel-metal hydride, sodium-sulfur, and redox flow batteries. ${ }^{1,2}$ Among the emerging technologies that are considered promising for stationary energy storage are dual-ion batteries (DIBs) $)^{3,4}$ and in particular graphite dual-ion batteries (GDIBs). ${ }^{5}$ GDIBs offer a maximum capacity of $\sim 140-150 \mathrm{mAh} \mathrm{g}^{-1}$; combining this with a high operational voltage $\left(\sim 4.5 \mathrm{~V}\right.$ vs $\left.\mathrm{Li}^{+} / \mathrm{Li}^{0}\right)$ and an optimized cell design results in a competitive energy density ranging from 210 to $260 \mathrm{Wh} \mathrm{L}^{-1}$. 4,6 The energy density is lower compared to most $\mathrm{Li}$-ion systems $\left(\sim 400 \mathrm{Wh} \mathrm{L}^{-1}\right)$, but is compensated by the environmental and cost benefits associated with GDIBs, as the use of expensive transition metal oxides can be eliminated and cheaper resources can be used. $^{4,6}$
The mechanism of charge storage in the positive electrode in GDIBs relies on the reversible intercalation of anions into the layered structure of graphite. Graphite is oxidized during charge accompanied by anion intercalation, as shown by eq 1 . In the negative electrode, reduction of graphite takes place with concurrent $\mathrm{Li}^{+}$intercalation according to eq 2 .

$$
\begin{aligned}
& x \mathrm{~A}^{-}+\text {Graphite } \leftrightarrow \mathrm{A}_{x} \text { Graphite }+x \mathrm{e}^{-} \\
& x \mathrm{Li}^{+}+x \mathrm{e}^{-}+\text {Graphite } \leftrightarrow \mathrm{Li}_{x} \text { Graphite }
\end{aligned}
$$

In eq 1 , “ $\mathrm{A}^{-}$” stands for the anion intercalant such as $\mathrm{PF}_{6}{ }^{-}, \mathrm{FSI}$, or TFSI. When discharging, the DIB cell undergoes the reverse reactions leading to recombination of anions and cations in the

Received: October 16, 2020

Accepted: January 4, 2021

Published: January 12, 2021

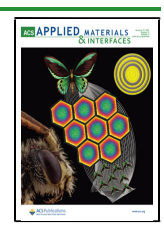


electrolyte. Therefore, the electrolyte in GDIBs not only conducts ions between the electrodes but also constitutes a vital part of the active material needed for electrochemical energy storage. For this particular reason, mostly concentrated electrolytes are employed in GDIBs, as they can supply a sufficient amount of ions to sustain extended battery performance. $^{7-10}$

Studies on anion intercalated graphite have been welldocumented, and the operating mechanism of GDIBs was patented already in 1989 by McCullough et al. ${ }^{11}$ However, the practical application of these devices is still under development. Operational challenges are associated with the unusually high working voltage $\left(>4.4 \mathrm{vs} \mathrm{Li}^{+} / \mathrm{Li}^{0}\right)$ required for anion intercalation and the poor reversibility of anion intercalation in graphite. Common electrolytes used in lithium-ion batteries consist of carbonate solvents which are prone to decomposition beyond $4.0 \mathrm{~V}$, resulting in a poor Coulombic efficiency $(<90 \%)$ and capacity retention in GDIBs. ${ }^{12}$ Solvents prone to oxidation aggravate self-discharge, making the longterm storage of charged GDIBs problematic. ${ }^{3}$ Further limitations include structural degradation associated with the irreversibility of the anion intercalation and solvent cointercalation into the graphite positive electrode, ${ }^{14}$ as well as corrosion of the $\mathrm{Al}$ current collector. ${ }^{15} \mathrm{~A}$ number of approaches have, however, been proposed to increase the stability and lifetime of GDIBs. Notably, studies have focused on the use of (1) small, planar anion intercalants, ${ }^{16,17}$ (2) electrolyte solvents unlikely to cointercalate in the graphitic cathode, $^{18}$ (3) concentrated electrolytes and ionic liquids, ${ }^{8,10}$ (4) surface-passivating additives, ${ }^{19-21}$ and (5) morphological tailoring of the graphite positive electrode..$^{22-24}$

While the nature of the cathode-electrolyte interphase (CEI) has been investigated for transition metal oxide (TMO) cathodes in commercial electrolytes (for example, $1 \mathrm{M} \mathrm{LiPF}_{6}$ in EC/DEC), ${ }^{25,26}$ few similar studies exist for GDIBs. For instance, $\mathrm{Li}$ et al. designed an interphase layer on the graphite positive electrode by cycling in the voltage range of $0.3-2.0 \mathrm{~V}$ versus $\mathrm{Li}^{+} / \mathrm{Li}^{0}$ in $1 \mathrm{M} \mathrm{LiPF} 6$ in ethyl methyl carbonate (EMC). ${ }^{27}$ Such modification of the CEI resulted in a $12 \%$ increase in the specific capacity and a capacity retention of $>98 \%$ over 2000 cycles. This highlights the importance of using CEI-generating electrolyte additives for improving the performance of GDIBs.

The stability of the $\mathrm{Al}$ current collector is also critical when

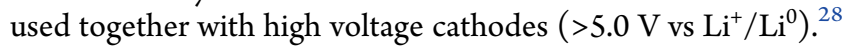
Commercial electrolytes are based on $\mathrm{LiPF}_{6}$, which inhibits $\mathrm{Al}$ corrosion through the buildup of an $\mathrm{AlF}_{3}$ passivating layer, a process triggered by anion decomposition. ${ }^{29}$ However, the reactivity of the $\mathrm{PF}_{6}{ }^{-}$anion and its high sensitivity to traces of

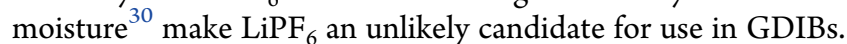
More chemically stable lithium salts, such as $\mathrm{LiN}\left(\mathrm{SO}_{2} \mathrm{~F}\right)_{2}$ (LiFSI) and $\mathrm{LiN}\left(\mathrm{SO}_{2} \mathrm{CF}_{3}\right)_{2}$ (LiTFSI), have demonstrated higher oxidative stability and a more reversible anion intercalation into graphite. In contrast, these salts aggravate the corrosion of the $\mathrm{Al}$ current collector. The current collector degradation has been attributed to pitting corrosion initiated by $\mathrm{Cl}^{-}$impurities, frequently present in these salts, ${ }^{31,32}$ and to anodic dissolution, as the native $\mathrm{Al}_{2} \mathrm{O}_{3}$ layer reacts with the anions, forming the soluble complexes $\left(\left[\mathrm{Al}(\mathrm{FSI})_{x}\right]^{3-x}\right.$ and $\left.\left[\mathrm{Al}(\mathrm{TFSI})_{x}\right]^{3-x}\right) .{ }^{33}$ Recent studies have demonstrated that the stabilization of the Al current collector can be achieved in concentrated electrolytes consisting of LiFSI/LiTFSI salts in carbonate solvents and in ionic liquids, as the solubility of the
$\mathrm{Al}^{3+}$ complexes decreases significantly in the absence of coordinating solvent molecules. 34,35

This work aims to understand the nature of the CEI in GDIBs using X-ray photoelectron spectroscopy (XPS). Experiments have been performed on two types of electrodes based on highly ordered pyrolytic graphite (HOPG) and microcrystalline KS6 graphite. The monolithic HOPG was cycled in $1 \mathrm{M} \mathrm{LiFSI}$ in $\mathrm{Pyr}_{14}$ FSI (1-butyl-1-methylpyrrolidinium bis(fluorosulfonylimide)) and served as a model system for analysis of anion-intercalated graphite in the absence of solvent decomposition products, carbon black, and binder. The composite graphite electrodes (composed of KS6 graphite, carbon black, and CMC binder) were cycled in both dilute and concentrated solutions of $\mathrm{LiPF}_{6}, \mathrm{LiFSI}$ and LiTFSI in a 1:1 ( $v /$ $v$ ) mixture of ethylene carbonate (EC) and diethyl carbonate (DEC), as well as in an ionic liquid electrolyte (1 M LiFSI in $\mathrm{Pyr}_{14} \mathrm{FSI}$ ). Surface characterizations of the electrodes, in their charged and discharged states, were undertaken using in-house XPS to gain insight into the nature and evolution of the CEI. It is expected that these results will benefit efforts to design longlife GDIBs through artificially created, thin CEI layers that are selectively permeable to anions.

\section{EXPERIMENTAL SECTION}

2.1. Cell Preparation. 2.1.1. Electrode Fabrication. Two types of graphite-positive electrodes were prepared, based on either monolithic HOPG (Agar Scientific) or KS6 graphite (Timcal, Imerys). HOPG was used since it is nearly ideal as substrate for XPS studies. KS6 was employed due to its promising electrochemical performance in GDIBs. The HOPG was cut into electrode pieces (approximately 5 $\mathrm{mm} \times 5 \mathrm{~mm} \times 2 \mathrm{~mm}$ in size) with a scalpel, dried at $120{ }^{\circ} \mathrm{C}$ for $12 \mathrm{~h}$ under vacuum, and stored in an Ar-filled glovebox $\left(\mathrm{O}_{2}<1 \mathrm{ppm}, \mathrm{H}_{2} \mathrm{O}\right.$ $<1 \mathrm{ppm})$. Composite electrodes were prepared from a slurry consisting of $90 \%$ graphite, $6 \%$ Super P carbon (Alfa Aesar), $4 \%$ sodium carboxymethyl cellulose (CMC, Leclanché), and $3 \mathrm{~mL}$ of a 9:1 solution of deionized water and ethanol, which was homogenized using a Vortex Genie2 mixer. The slurry was cast onto carbon-coated $\mathrm{Al}$ foil (MTI) and dried at ambient condition. Electrode disks with a diameter of $13 \mathrm{~mm}$ were punched, dried at $120{ }^{\circ} \mathrm{C}$ over $12 \mathrm{~h}$ under vacuum, and stored in an Ar-filled glovebox. Li disks (Cyprus Foote Mineral) with a diameter of $13 \mathrm{~mm}$ were used as the counter and reference electrodes.

2.1.2. Electrolyte Preparation. Three types of salts, namely, $\mathrm{LiPF}_{6}$ (Aldrich, >99.99\%), LiTFSI (BASF), and LiFSI (Suzhou Fluolyte, $>99.9 \%)$ were dissolved in a 1:1 $(v / v)$ EC (Gotion)/DEC (Gotion) solvent mixture to prepare electrolytes with concentrations of 1,2 , and $4 \mathrm{M}$. The salts dried in a vacuum oven at $120^{\circ} \mathrm{C}$ over $12 \mathrm{~h}$ for $\mathrm{LiPF}_{6}, 120^{\circ} \mathrm{C}$ over $48 \mathrm{~h}$ for LiTFSI, and $80^{\circ} \mathrm{C}$ over $72 \mathrm{~h}$ for LiFSI. The electrolyte solvent was dried over molecular sieves for at least 48 h (resulting in $\mathrm{H}_{2} \mathrm{O}$ content $<1 \mathrm{ppm}$ ) and filtered through $200 \mathrm{~nm}$ PTFE membranes prior to mixing with the salt. To prepare the concentrated electrolytes, the solutions were heated to $60{ }^{\circ} \mathrm{C}$ for LiTFSI and LiFSI and to $45{ }^{\circ} \mathrm{C}$ in the case of $\mathrm{LiPF}_{6}$. An electrolyte based on ionic liquid with the formulation $1 \mathrm{M} \mathrm{LiFSI}$ in $\mathrm{Pyr}_{14} \mathrm{FSI}$ (Solvionic) was also considered in this study. The $\mathrm{H}_{2} \mathrm{O}$ content in the LiFSI- and LiTFSI-based electrolytes was determined using a $756 \mathrm{Karl}$ Fischer coulometer (Metrohm) and varied between 15 and $60 \mathrm{ppm}$ depending on the electrolyte concentration. The $\mathrm{LiPF}_{6}$ based electrolytes and the $1 \mathrm{M} \mathrm{LiFSI}$ in $\mathrm{Pyr}_{14}$ FSI showed a water content below $2 \mathrm{ppm}$. All electrolyte preparation took place in the glovebox.

2.1.3. Cell Fabrication. Pouch cells were assembled using a KS6 graphite cathode as the working electrode and a $26 \mathrm{~mm}$ glass fiber separator $(240 \mu \mathrm{m}$ thick, Whatman) impregnated with $150 \mu \mathrm{L}$ of electrolyte. The counter and reference electrodes consisted of metallic $\mathrm{Li}$, and the experiments took place in a two-electrode half-cell format, unless otherwise stated. The final sealing pressure was $5 \mathrm{mbar}$. All cells containing the ionic liquid and the highly concentrated $4 \mathrm{M}$ 
(a)

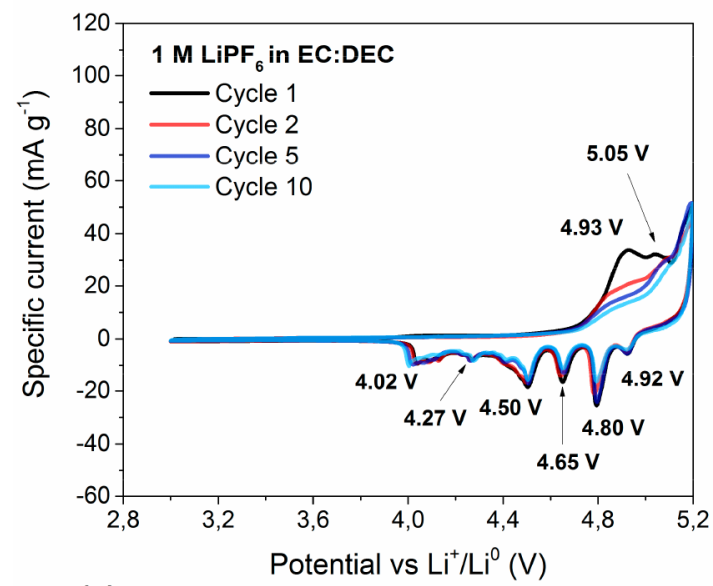

(c)

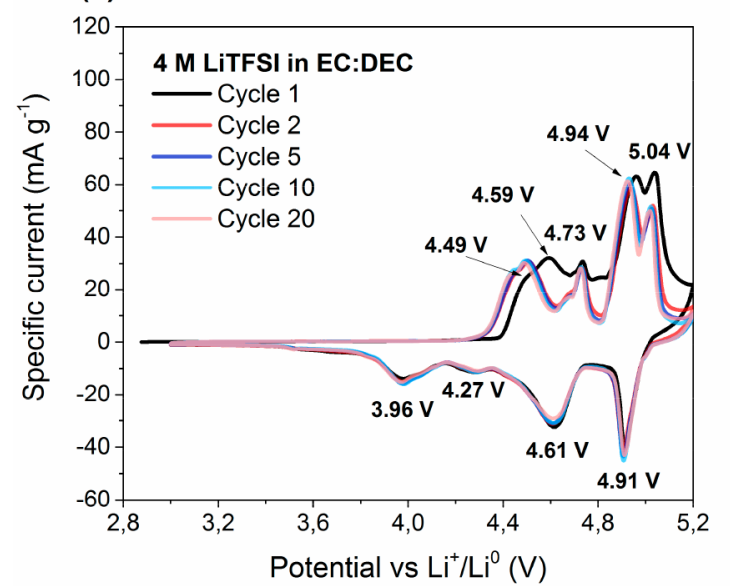

(e)

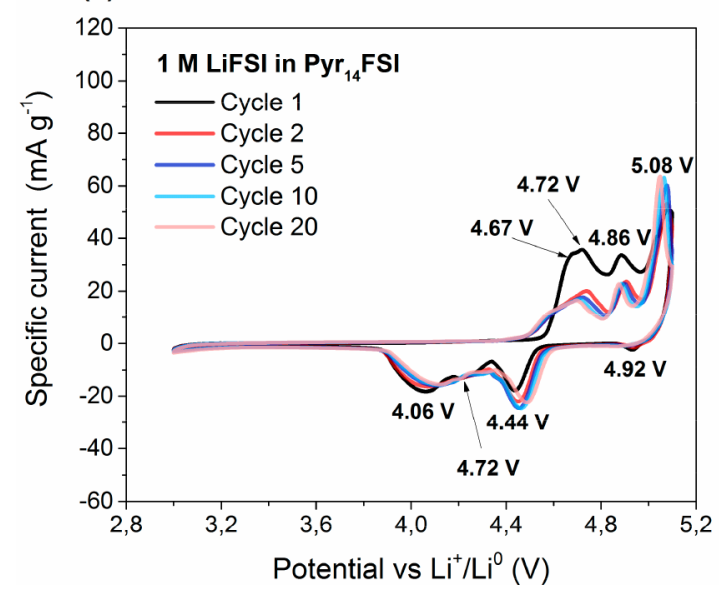

(b)

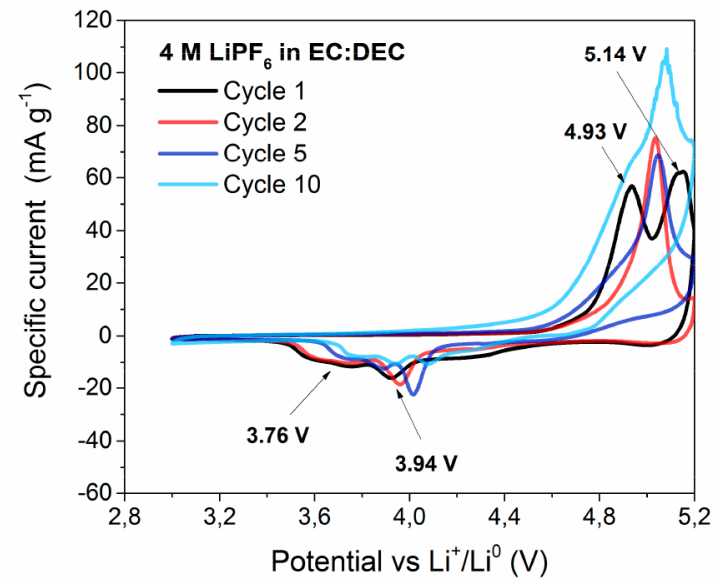

(d)

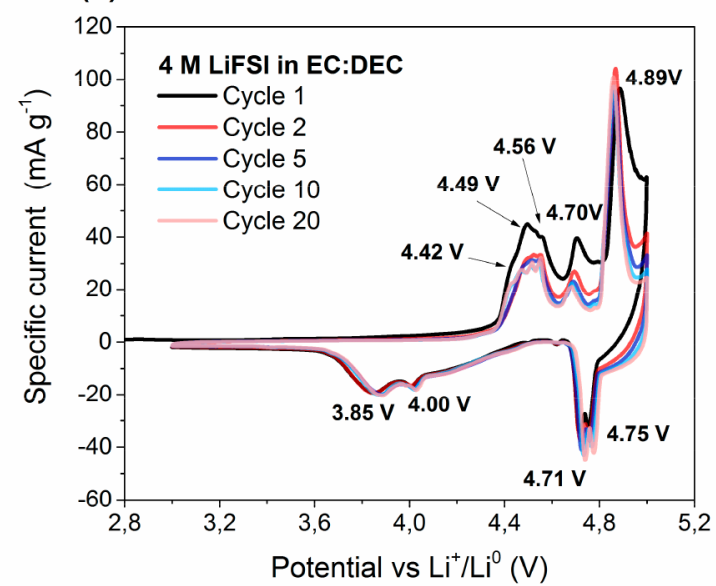

(f)

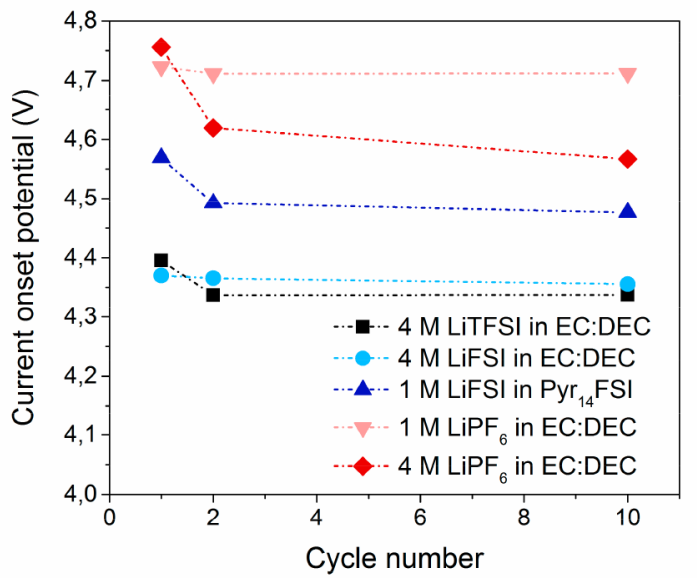

Figure 1. Anion intercalation in KS6 graphite from (a) $1 \mathrm{M} \mathrm{LiPF}_{6}$ in EC/DEC, (b) $4 \mathrm{M} \mathrm{LiPF}_{6}$ in EC/DEC, (c) $4 \mathrm{M} \mathrm{LiTFSI} \mathrm{in} \mathrm{EC/DEC,} \mathrm{(d)} 4 \mathrm{M}$ $\mathrm{LiFSI}$ in EC/DEC, and (e) $1 \mathrm{M} \mathrm{LiFSI}$ in Pyr ${ }_{14}$ FSI. The designated redox peak potentials correspond to the first CV cycle. In (f), evolution of the current onset potential during cycles 1,2 , and 10.

electrolytes were put in an oven at $55{ }^{\circ} \mathrm{C}$ for $20 \mathrm{~min}$ prior to electrochemical testing in order to ensure proper electrode wetting. The setup for the cells with an HOPG positive electrode was identical, with the only difference being that these were impregnated with 300 $\mu \mathrm{L}$ of electrolyte, due to the high electrode mass and thickness.

2.2. Electrochemical Characterization. Electrochemical testing was conducted using cyclic voltammetry and galvanostatic test protocols on MPG2 Biologic potentiostats and an Arbin BT cycler. Cyclic voltammograms were acquired at a scan rate of $0.050 \mathrm{mV} \mathrm{s}^{-1}$ and most chronopotentiometric measurements were conducted at a charge/discharge current of $10 \mathrm{~mA} \mathrm{~g}^{-1}$ of active material. HOPG electrodes were cycled with a lower charge/discharge current of $1 \mathrm{~mA}$ $\mathrm{g}^{-1}$. Spectroscopic and microscopic characterizations were performed for the galvanostatically cycled cells, unless otherwise stated.

2.3. X-ray Photoelectron Spectroscopy. 2.3.1. XPS on Monolithic Highly Oriented Pyrolytic Graphite Electrodes. To establish a basic understanding of the positive interface in GDIBs, initial XPS measurements were performed on HOPG electrodes. The elimination of the conducting additive and binder facilitated the spectral interpretation. HOPG electrodes were galvanostatically cycled (at $1 \mathrm{~mA} \mathrm{~g}^{-1}$ ) against $\mathrm{Li}$ and in $1 \mathrm{M} \mathrm{LiFSI}$ in Pyr ${ }_{14} \mathrm{FSI}$, to avoid $\mathrm{C} 1 \mathrm{~s}$ contributions from the salt and/or carbonate solvents. 
Spectra of the pristine, electrolyte soaked, fully charged $\left(5.1{\mathrm{~V} \mathrm{vs} \mathrm{Li}^{+} /}^{\text {/ }}\right.$ $\left.\mathrm{Li}^{0}\right)$, and fully discharged $\left(3.0 \mathrm{~V}\right.$ vs $\left.\mathrm{Li}^{+} / \mathrm{Li}^{0}\right)$ HOPG (basal plane) were acquired to understand the effect of state-of charge. The "soaked" samples were assembled in half-cell format and left to rest for $24 \mathrm{~h}$ prior to disassembly. Before analysis, the HOPG electrodes were cleaved (by carefully applying pressure with a scalpel on the 2 $\mathrm{mm}$ thick side), and no washing procedures were used. The freshly exposed surface was used for the analysis. All samples were handled under a glovebox atmosphere and brought to the spectrometer (PHI $5500)$ in an airtight transfer shuttle. Monochromatic $\mathrm{Al} \mathrm{K} \alpha$ radiation was used for the measurements $(h v=1486.7 \mathrm{eV})$ at an emission angle of $45^{\circ}$. Fitting was performed with Igor Pro (v. 6.37), using a Gaussian/Lorentzian mixed line shape after the subtraction of a Shirley background. The $\mathrm{N}$ 1s peak belonging to nongrounded, surface salt residues was used for calibration, in lieu of a method to accurately determine the Fermi level. All spectra were normalized with respect to the highest peak.

2.3.2. XPS on Composite Graphite Electrodes. Analyzed samples included the pristine electrode as well as soaked and cycled electrodes

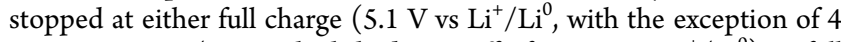
$\left.\mathrm{M} \mathrm{LiFSI} \mathrm{in} \mathrm{EC/DEC} \mathrm{which} \mathrm{had} \mathrm{a} \mathrm{cutoff} \mathrm{of} 4.95 \mathrm{~V} \mathrm{vs} \mathrm{Li}^{+} / \mathrm{Li}^{0}\right)$ or full discharge $\left(3.0 \mathrm{~V} \mathrm{vs} \mathrm{Li}^{+} / \mathrm{Li}^{0}\right)$. The charged and discharged states were analyzed for cycles 1,2, and 10, to determine the impact of repeated cycling on the CEI. All electrodes were recovered in a glovebox and soaked for $12 \mathrm{~h}$ in $1 \mathrm{~mL}$ of dimethyl carbonate (DMC, $\geq 99 \%$, SigmaAldrich), prior to drying and analysis. The sample transfer, measurement and fitting procedures were kept the same as for HOPG.

2.4. Transmission Electron Microscopy. The pristine KS6 graphite powder and composite electrodes cycled in $4 \mathrm{M}$ LiTFSI in EC/DEC, $1 \mathrm{M} \mathrm{LiFSI}$ in $\mathrm{Pyr}_{14} \mathrm{FSI}$, and $4 \mathrm{M}$ LiFSI in EC/DEC were analyzed with TEM using a $200 \mathrm{kV}$ field-emission JEOL $2100 \mathrm{~F}$ microscope. The graphite electrodes were galvanostatically cycled versus $\mathrm{Li}$ at a specific current of $10 \mathrm{~mA} \mathrm{~g}^{-1}$. The cells were stopped after one full cycle (at $3.0 \mathrm{~V} \mathrm{vs} \mathrm{Li}^{+} / \mathrm{Li}^{0}$ ) and opened in an Ar-filled glovebox. After rinsing with DMC to wash away electrolyte salt and drying at ambient conditions, the composite films were removed from the current collector, redispersed in DMC and sonicated for $30 \mathrm{~min}$. A few ( 2 to 3 ) drops of the dispersions were deposited on the TEM grids (with holey carbon films on top) and transferred to the microscope without exposure to air.

\section{RESULTS AND DISCUSSION}

3.1. Electrochemical Anion Intercalation and Associated Structural Changes. The cyclic voltammograms $(\mathrm{CV})$ in Figure 1 revealed the inherent dependence of the reversibility and kinetics of electrochemical anion intercalation on the chemical nature of the anion and its concentration in the electrolyte. Anion characteristics such as charge density, ionic size, stereochemistry, and solvent coordination determine the ease of intercalation into the graphitic host, usually manifested in the onset overpotential. ${ }^{18}$ Here, the intercalation overpotential during the first charge decreased in the order $\mathrm{PF}_{6}{ }^{-}>\mathrm{FSI}>\mathrm{TFSI}$. Generally, the species with a smaller ionic radius and a higher charge density such as $\mathrm{PF}_{6}{ }^{-}$and FSI could be subjected to stronger interactions with solvent molecules and $\mathrm{Li}^{+}$compared to TFSI, hence exerting an increased drag force in the electrolyte. ${ }^{16}$ The impact of the anion drag force on the intercalation overpotential could be seen clearly by comparing the $4 \mathrm{M} \mathrm{LiFSI}$ in EC/DEC system to the $1 \mathrm{M} \mathrm{LiFSI}$ in $\mathrm{Pyr}_{14} \mathrm{FSI}$ system. The latter exhibits an overpotential almost

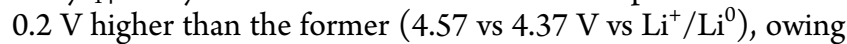
to the absence of a conventional solvent in the ionic liquid. In this case, FSI is surrounded by 1-butyl-1methylpyrrolydinium cations (instead of neutral solvent molecules such as EC and $\mathrm{DEC})$, hence increasing the resistance against intercalation in graphite.
The marked increase in intercalation overpotentials in both

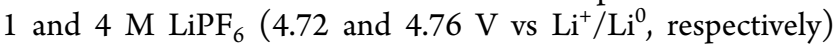
could be due to the formation of a thick interphase on the positive graphite electrode, leading to concentration polarization across the CEI and impedance of anion intercalation. The poor reversibility exhibited by the dual-ion cell (Figure la,b) was particularly pronounced in the case of $4 \mathrm{M} \mathrm{LiPF}_{6}$, where an asymmetry in the oxidation and reduction peaks was observed along with a large peak-to-peak voltage difference. Moreover, the majority of the anions were de-intercalated below $4.0 \mathrm{~V}$, which could be indicative of inefficient ion conduction across the CEI layer. ${ }^{22,36}$ In $4 \mathrm{M}$ LiTFSI and $4 \mathrm{M}$ LiFSI electrolytes (Figure 1c,d), anion cycling occurred more readily and reversibly as demonstrated by the low onset overpotential. Multiple redox peaks appeared during both anion intercalation and deintercalation as different graphite intercalation compounds (GICs) formed. Anion intercalation from the $4 \mathrm{M} \mathrm{LiFSI}$ in EC/DEC showed similar characteristics to the $4 \mathrm{M} \mathrm{LiTFSI}$ in EC/DEC electrolyte. It should, however, be noted that anion extraction appeared to be more sluggish and that the majority of anions could be released into the

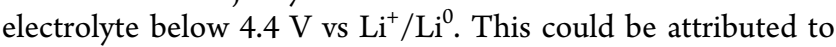
the higher charge density of the FSI anion that caused a stronger interaction with the graphite host. In the ionic liquid electrolyte (Figure 1e), a similar phenomenon was noted but with substantially higher overpotential for deintercalation. Apart from the high charge density, the impaired kinetics of FSI anion intercalation/deintercalation in the ionic liquid could further be ascribed to the high viscosity and possibly the ion pairing which decreased the ionic conductivity. ${ }^{37}$ Spectroscopic evidence confirming the reversible anion intercalation for the electrolyte systems studied is provided in Figure S26, which shows the Raman spectra of fully charged/discharged electrodes for cycles 1, 2, and 10. On the basis of the changes in the intensity of the defect ( $D$ band) and the intercalation component of the graphite band ( $\mathrm{D}^{\prime}$ band), FSI intercalation was found to cause the least severe damages to the layered graphite structure, though both TFSI and $\mathrm{PF}_{6}{ }^{-}$ intercalations were also observed to be reversible. Despite the good electrochemical reversibility and the Raman data showing that the material was still highly graphitic after cycling, irreversible structural changes were observed for a selection of the cycled graphite cathodes studied through ex situ X-ray diffraction (XRD, Figure S27). Initially, the splitting of the (002) reflection located at $26.49^{\circ}(3.4 \AA)$ into the $(00 n+1)$ and $(00 n+2)$ components was observed, which provided further structural evidence of the anion intercalation and

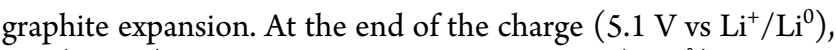
the $(00 n+1)$ reflection had shifted to $22.13^{\circ}(4.0 \AA)$, and the $(00 n+2)$ reflection shifted to $33.15^{\circ}(2.7 \AA)$ for graphite cycled in $4 \mathrm{M}$ LiTFSI in EC/DEC (Figure S27a). Upon the subsequent discharge, the $(00 n+1)$ and $(00 n+2)$ decreased in intensity, and the 002 component reappeared at approximately its original position $\left(26.45^{\circ}\right)$. However, considerable broadening could be observed, which indicated that exfoliation and disorder increased, as a consequence of the graphite interlayer expansion. The overall trend was similar for graphite cathodes cycled in $4 \mathrm{M} \mathrm{LiFSI}$ in EC/DEC and $1 \mathrm{M} \mathrm{LiFSI}$ in $\mathrm{Pyr}_{14} \mathrm{FSI}$ (Figure S27b,c). This result remains to be confirmed with in situ XRD studies in the future.

Returning to the electrochemistry, significant differences were observed in the magnitudes of the background current recorded at the end of charge for the concentrated electrolytes 
(a)

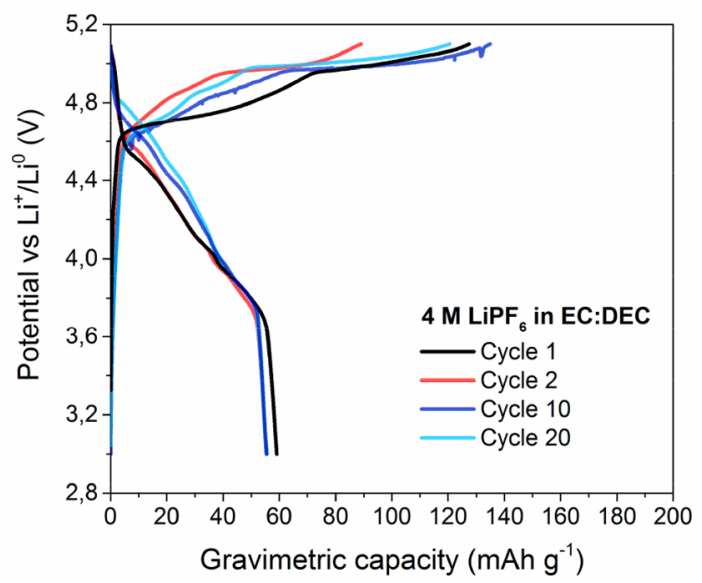

(c)
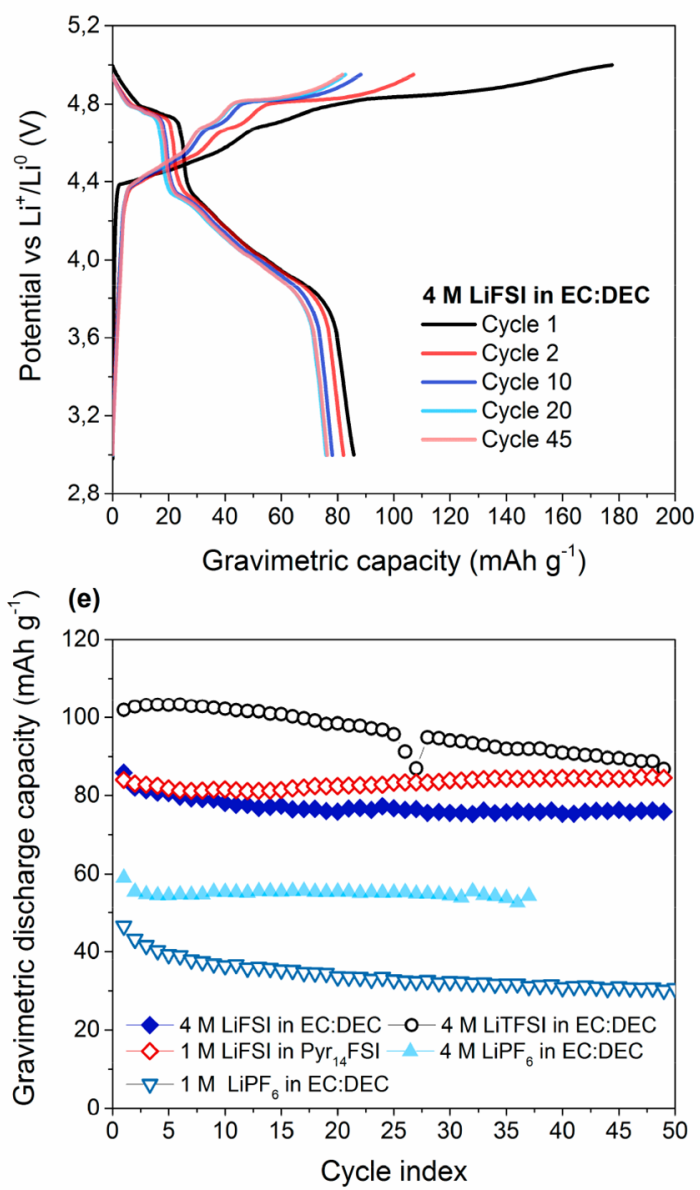

(b)

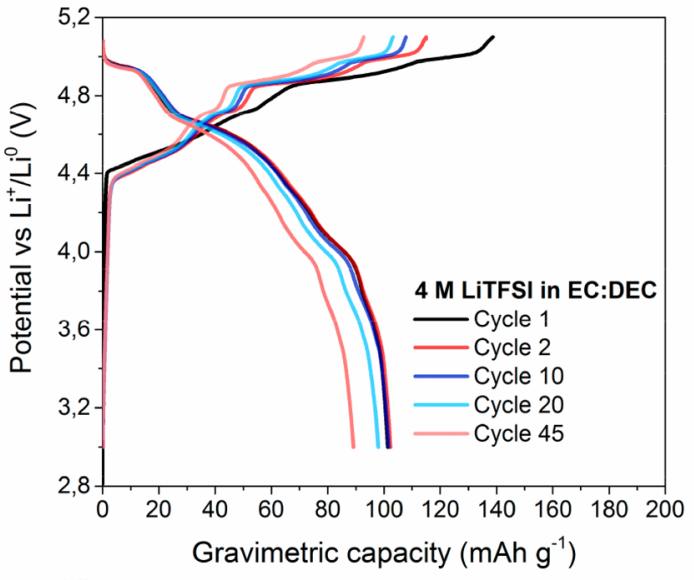

(d)
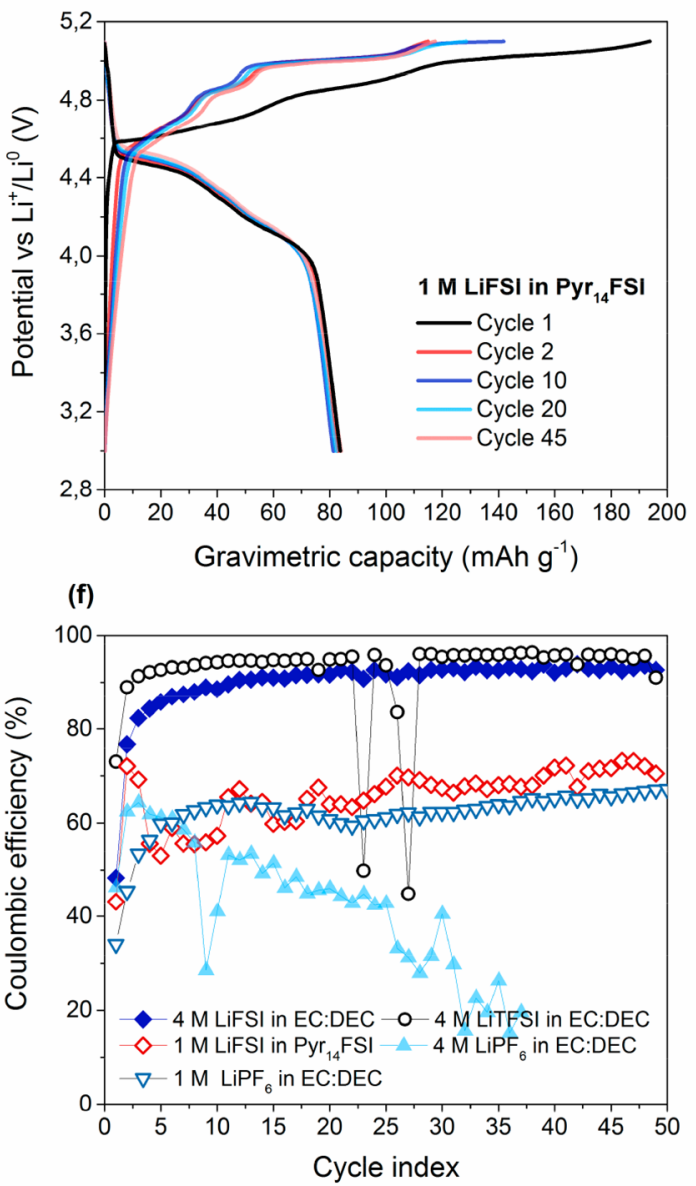

Figure 2. Galvanostatic charge-discharge profiles of KS6 graphite cycled in (a) $4 \mathrm{M} \mathrm{LiPF}_{6}$ in EC/DEC, (b) $4 \mathrm{M} \mathrm{LiTFSI} \mathrm{in} \mathrm{EC/DEC,} \mathrm{(c)} 4 \mathrm{M}$ LiFSI in EC/DEC and (d) 1 M LiFSI in Pyr ${ }_{14}$ FSI. (e) Associated gravimetric capacities. (f) Coulombic efficiencies for extended cycling.

(Figure 1c-e). According to these, the 4 M LiTFSI electrolyte appeared to be more stable than both the $4 \mathrm{M} \mathrm{LiFSI}$ and IL electrolytes. The background current at high potentials, normally linked to solvent decomposition and $\mathrm{Al}$ current collector corrosion, was lower for the $4 \mathrm{M}$ LiTFSI case, even when the voltage was swept beyond $4.8 \mathrm{~V}$. This is in line with results from the $\mathrm{Al}$ current collector stability test (Figure S1c$\mathrm{g}$ ), in which the $4 \mathrm{M}$ LiTFSI electrolyte resulted in oxidative currents which were at least an order of magnitude lower compared to the other compositions based on sulfonimide salts. A maximum peak current of $\sim 125 \mu \mathrm{A} \mathrm{cm}^{-2}$ was observed for the $4 \mathrm{M} \mathrm{LiTFSI}$ in EC/DEC system as opposed to $1 \mathrm{~mA}$ $\mathrm{cm}^{-2}$ recorded for the IL electrolyte. Nevertheless, it appeared that passivation of the current collector surface was achieved even in the $4 \mathrm{M} \mathrm{LiFSI}$ in EC/DEC and $1 \mathrm{M} \mathrm{LiFSI}$ in $\mathrm{Pyr}_{14} \mathrm{FSI}$ electrolytes resulting in lower oxidative currents in the subsequent cycles (Figure S1d,g). The structural integrity of the Al current collector in these three electrolytes was confirmed using post-mortem SEM analyses performed after three CV cycles (Figure S13b,f,h), which revealed a surface very similar to that of pristine Al (Figure S13a). This was in contrast to the $1 \mathrm{M} \mathrm{LiFSI}$ and $1 \mathrm{M}$ LiTFSI electrolytes that 
caused severe damage to the current collector in the form of corrosion pits as large as $100 \mu \mathrm{m}$ (Figure S13e,g). In addition, the electrodes cycled in $4 \mathrm{M} \mathrm{LiFSI/LiTFSI} \mathrm{in} \mathrm{EC/DEC} \mathrm{and} \mathrm{in}$ IL remained largely unaffected as revealed in the SEM images taken after the 10th charge, apart from certain surface roughness and exfoliation of the cycled graphite particles (Figure S14a,b,e,f). This could be indicative of solvent decomposition in the electrode, resulting in the formation of "blisters". ${ }^{8}$ Moreover, while the SEM/EDS of graphite electrodes cycled in concentrated $4 \mathrm{M} \mathrm{LiFSI}$ and $4 \mathrm{M}$ LiTFSI provided no clear evidence of current collector corrosion (see Figures S14, S18, and S19), the corresponding SEM images for the IL electrolyte (Figures S14 and S15) revealed the presence of a decomposition product rich in $\mathrm{Al}$ and FSI and hence indicated that the IL was not equally passivating. Finally, a last point in favor of using the highly concentrated version of the LiFSI/LiTFSI in EC/DEC electrolytes was that the anion intercalation could barely be observed in the most dilute versions $(1 \mathrm{M})$ of these electrolytes (Figure S2a,c). This was due not only to the side reactions taking place but also to the fact that a higher overpotential for anion intercalation was required in the dilute electrolytes, something that was confirmed by comparing these CVs to those of cells cycled at concentrations of $2 \mathrm{M}$ (Figure S2b,d) and $4 \mathrm{M}$ (Figure 1c,d).

Unlike the electrolytes based on LiFSI and LiTFSI, anion intercalation was observed even for the lower concentration 1 $\mathrm{M} \mathrm{LiPF}_{6}$ electrolyte. Unique to the $\mathrm{PF}_{6}{ }^{-}$anion especially in the presence of EC, decomposition reactions helped form protective layers on both the current collector and graphite electrode. The good passivation of the $\mathrm{Al}$ current collector in $\mathrm{LiPF}_{6}$-containing electrolytes was reflected in the low oxidative

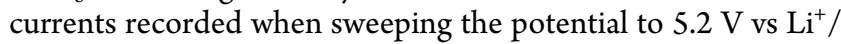
$\mathrm{Li}^{0}$ (Figure S1a,b). This was equally visible in the SEM micrographs of the current collector (Figure S13c,d) and the cycled graphite electrodes (Figure $\mathrm{S} 14 \mathrm{c}, \mathrm{d}$ ), in which no degradation of the $\mathrm{Al}$ or the active materials could be seen. In fact, it appeared that most surfaces in contact with $\mathrm{LiPF}_{6}$ containing electrolytes were covered with decomposition products. EDS imaging of cycled electrodes (Figures S16 and S17) indicated that this deposit was rich in $\mathrm{F}$ and $\mathrm{P}$ coming from the anion decomposition, as well as $\mathrm{O}$, which could originate from the carbonate solvents. Even though such a layer could protect the electrolyte from decomposition, it could also imply a higher resistance against anion conduction. This was observed in the CV of $1 \mathrm{M} \mathrm{LiPF}_{6}$ in EC/DEC (Figure 1a), which exhibited multiple peaks upon discharge, corresponding to at least 6 distinct staging steps. However, the staging behavior upon charge exhibited a less well-defined appearance in the $\mathrm{CV}$, meaning that the oxidation peaks were not well-separated. This indicated that the intercalation kinetics for $\mathrm{PF}_{6}^{-}$were more sluggish compared to the deintercalation step. In addition, the intercalation of $\mathrm{PF}_{6}^{-}$ was particularly difficult to observe during the course of the first cycle, since it was partially masked by the background current due to solvent decomposition. The background current due to electrolyte decomposition further increased for the $4 \mathrm{M}$ $\mathrm{LiPF}_{6}$ electrolyte (Figure $1 \mathrm{~b}$ ), indicating that the $\mathrm{PF}_{6}^{-}$anion triggered side reactions. The electrolyte decomposition did not appear to cease in the course of the first 10 cycles, making the $\mathrm{LiPF}_{6}$ in EC/DEC electrolytes unsuitable for practical applications.
Other essential performance descriptors which define the suitability of a given electrolyte and electrode in DIBs include the specific capacity, Coulombic efficiency (CE) and long-term cycling capability. Galvanostatic experiments conducted in half-cells using both dilute and concentrated electrolytes further indicated that the anions performed differently (Figure 2). The $\mathrm{PF}_{6}^{-}$anion had poor performance in terms of both discharge capacity and CE. In $1 \mathrm{M} \mathrm{LiPF}_{6}$, the $\mathrm{CE}$ reached $60 \%$, where it remained during prolonged cycling. The initial discharge capacity was $46 \mathrm{mAh} \mathrm{g}^{-1}$ which decreased to 31 $\mathrm{mAh} \mathrm{g}^{-1}$ over 45 cycles (Figures $2 \mathrm{e}, \mathrm{f}$ and S3). In the $4 \mathrm{M}$ $\mathrm{LiPF}_{6}$ electrolyte, the CE decreased from 60 to $20 \%$ over 40 cycles, while the discharge capacity stayed approximately constant at $55 \mathrm{mAh} \mathrm{g}^{-1}$ (Figure 2e,f). A drastic increase in polarization was observed in both electrolytes after the first cycle that was possibly due to the formation of SEI/CEI layers. These observations were again indicative of irreversible surface reactions and anion intercalation. In contrast, an initial discharge capacity of $86 \mathrm{mAh} \mathrm{g}^{-1}$ was obtained in the $4 \mathrm{M}$ $\mathrm{LiFSI}$ in EC/DEC. The initial CE was $\sim 50 \%$ and increased to $90 \%$ in the subsequent cycles. A similar discharge capacity was observed in the $1 \mathrm{M}$ LiFSI in $\mathrm{Pyr}_{14}$ FSI electrolyte $(84 \mathrm{mAh}$ $\left.\mathrm{g}^{-1}\right)$, but the CE remained low $(\sim 60-70 \%)$ throughout cycling. This could be partially due to insufficient surface passivation of the lithium negative electrode in the absence of the EC/DEC solvent mixture. ${ }^{39}$ However, the previously discussed evidence from SEM/EDS imaging and from the literature ${ }^{20}$ indicated that the $1 \mathrm{M} \mathrm{LiFSI}$ in $\mathrm{Pyr}_{14} \mathrm{FSI}$ electrolyte could not passivate the $\mathrm{Al}$ current collector to the same extent as the other electrolytes tested. Additional electrochemical experiments conducted to ensure the reliability of the $\mathrm{Li}$ reference electrode (Figures S7 and S8) and to investigate the origin of the poor CE (Figure S9) pinpointed parasitic reactions on the graphite cathode as the major problem. Here, it must also be repeated that galvanostatic tests for the $4 \mathrm{M}$ LiFSI in EC/DEC electrolyte were restricted within the potential range of 3.0-4.95 $\mathrm{V} \mathrm{vs} \mathrm{Li}^{+} / \mathrm{Li}^{0}$ (compared to all other electrolytes which were cycled to $\left.5.1 \mathrm{~V} \mathrm{vs} \mathrm{Li}^{+} / \mathrm{Li}^{0}\right)$. The reason for the different cutoff was that an extensive decomposition plateau was observed above $4.95 \mathrm{~V}$ vs $\mathrm{Li}^{+} / \mathrm{Li}^{0}$ (see Figure S4) for the $4 \mathrm{M} \mathrm{LiFSI}$ in EC/DEC electrolyte. The $4 \mathrm{M}$ LiTFSI system exhibited the highest initial discharge capacity (102 $\mathrm{mAh} \mathrm{g}^{-1}$ ) and $\mathrm{CE}(73 \%)$. In the subsequent cycles, the $\mathrm{CE}$ increased to $95 \%$ as the result of the excellent stability of the TFSI anion and its reversible intercalation in graphite. Further processing of the galvanostatic long-term cycling data (Figures S5 and S6) revealed that the TFSI anion exhibited a highly stable average charge and discharge voltage, as well as the smallest voltage hysteresis among the tested electrolytes. Last, preliminary experiments using a constant-current, constantvoltage (CCCV) protocol (Figures S10 and S11) indicated that there is room for additional performance enhancement, which proved to be especially true for the HCEs based on LiFSI and LiTFSI. In these electrolytes, the introduction of a constant voltage step at the end of discharge led to a significant increase in recovered discharge capacity. Hence, the CE may be further improved by giving the trapped anions additional time to deintercalate.

A detailed XPS study is presented in the following section to better understand the origin of performance differences and the chemical nature of the CEI in the electrolytes investigated so far. 
(a)

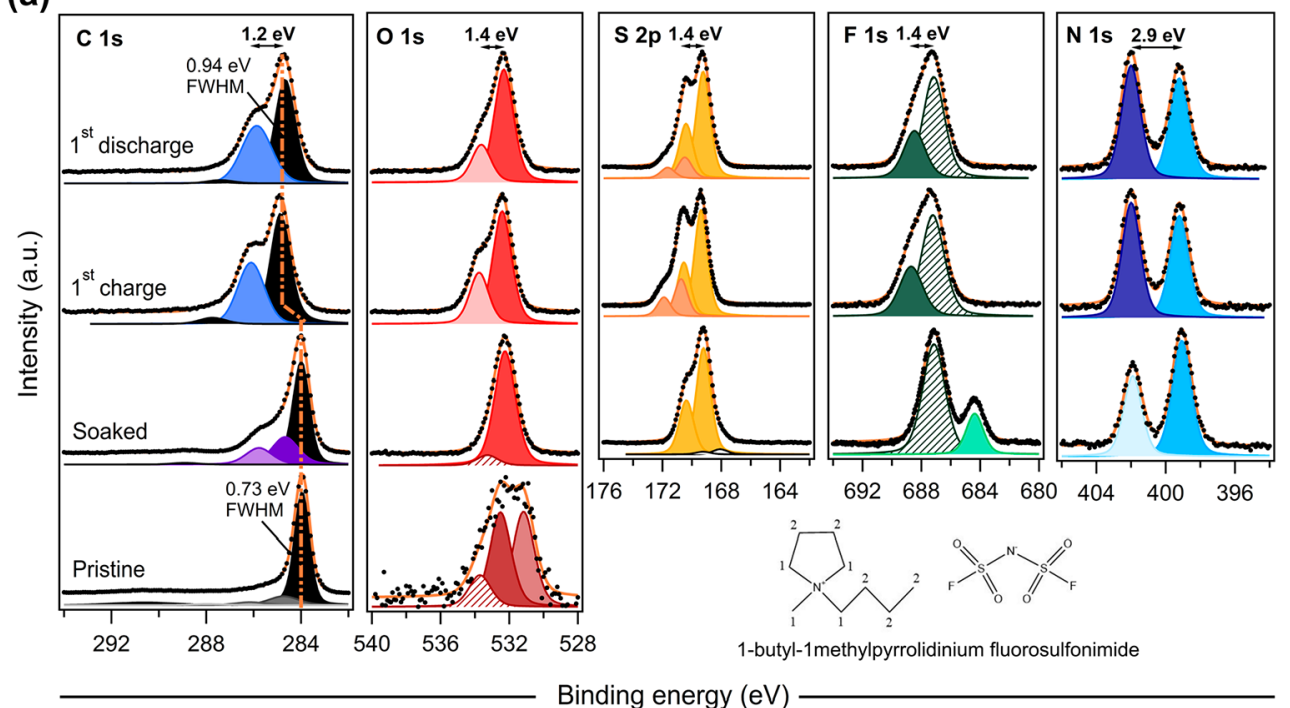

(b)

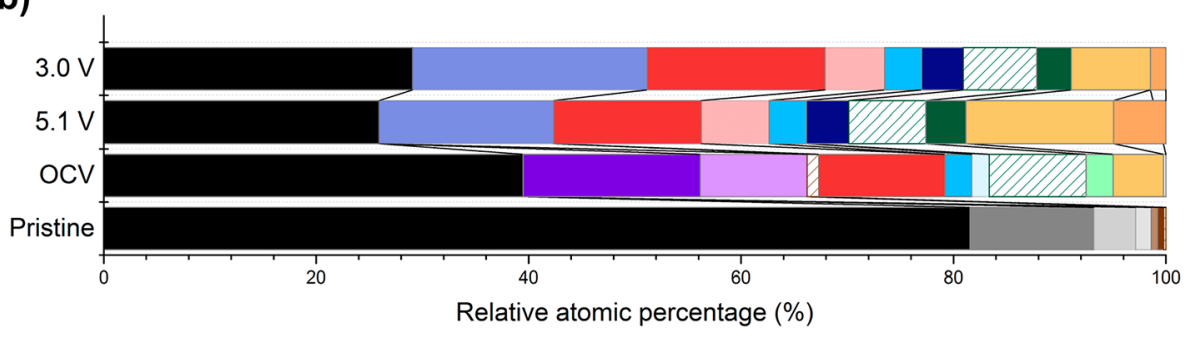

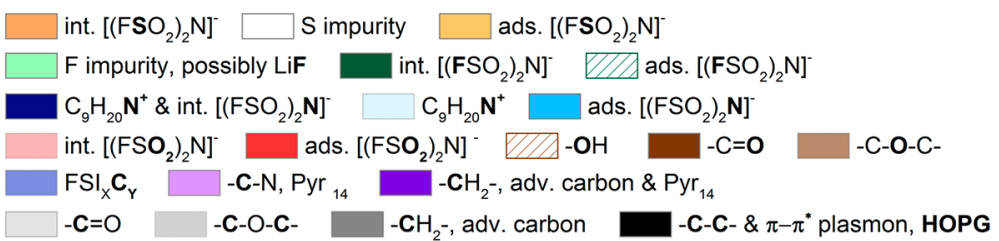

Figure 3. Investigating the surface composition and evolution of HOPG electrodes: (a) normalized S 2p, F 1s, N 1s, O 1s, and C 1s core-level X-ray photoelectron spectra of pristine, soaked, fully charged $\left(5.1 \mathrm{~V} \mathrm{vs} \mathrm{Li}^{+} / \mathrm{Li}^{0}\right)$, and fully discharged $\left(3.0 \mathrm{~V} \mathrm{vs} \mathrm{Li}^{+} / \mathrm{Li}^{0}\right)$ HOPG samples. (b) $\mathrm{Relative}$ atomic percentages of each chemical species present on the surface of HOPG samples in (a).

\subsection{CEI Probed by X-ray Photoelectron Spectrosco-} py. 3.2.1. Surface Analysis of Anion-Intercalated Highly Oriented Pyrolytic Graphite. XPS was performed on monolithic, highly oriented pyrolytic graphite (HOPG) electrodes with $1 \mathrm{M} \mathrm{LiFSI}$ in $\mathrm{Pyr}_{14} \mathrm{FSI}$ as the electrolyte for identification of binding energy positions for intercalated anions and anions in electrolyte residues on the surface. The topmost surface of cycled HOPG that was in direct contact with the electrolyte was cleaved to get rid of decomposition residues, thereby exposing a fresh surface for analysis. With such an experimental design, the photoelectron signals originated largely from the intercalated graphite. The XPS study on HOPG electrodes at different states-of-charge is summarized in Figure 3.

The basal plane of HOPG primarily showed a sharp peak (a fwhm of $0.73 \mathrm{eV}$ ) due to $\mathrm{sp}^{2}$-hybridized carbons, located around $284.0 \mathrm{eV}$ in the $\mathrm{C} 1 \mathrm{~s}$ spectrum. Other, much less intense peaks assigned to $\mathrm{sp}^{3}$-hybridized carbon from adventitious carbon and edge terminations $(285.0 \mathrm{eV})$ and plasmon features $(\sim 290.0 \mathrm{eV})$ could also be observed. After soaking in the electrolyte, the pristine HOPG exhibited more pronounced secondary carbon features originating from
$-\mathrm{CH}_{2}-$ groups $(285 \mathrm{eV})$ and the $-\mathrm{C}-\mathrm{N}(+)-$ bonds $(\sim 286.0 \mathrm{eV})$ of the 1-butyl-1-methylpyrrolidinium $\left(\mathrm{Pyr}_{14}{ }^{+}\right)$ in the ionic liquid. ${ }^{40}$ Integration of the areas under the peaks resulted in a 57:43 ratio of $-\mathrm{CH}_{2}-$ and $-\mathrm{C}-\mathrm{N}(+)-$ bonds, which was in good agreement with the 55:45 ratio calculated from stoichiometric considerations. As expected for $\mathrm{Pyr}_{14}$-FSI, two different nitrogen species were observed in the $\mathrm{N}$ 1s spectrum of the ionic liquid: one from the $\mathrm{Pyr}_{14}{ }^{+}$ring located around $401.8 \mathrm{eV}$ and another due to the imide in the FSI anion at $399.1 \mathrm{eV}$. The intensity of the $\mathrm{C} 1 \mathrm{~s}$ peaks from $\mathrm{Pyr}_{14}{ }^{+}$ correlated well with the intensity of the $\mathrm{N} 1$ s peak at $401.8 \mathrm{eV}$. After correcting for the atomic sensitivity, the $\mathrm{C} 1 \mathrm{~s}$ peaks made up $92 \%$ of the total integrated area, while the $\mathrm{N}$ 1s peak amounted to $8 \%$, which was very close to the $9: 1$ ratio expected for carbon and nitrogen in $\mathrm{Pyr}_{14}{ }^{+}$ring. As the only source of sulfur and fluorine atoms, the FSI anion showed a doublet in the S 2p spectrum, located around $169.2 \mathrm{eV}$ due to the sulfonyl moiety, and one main peak with an impurity feature around $687.2 \mathrm{eV}$ due to the fluorine bonded to sulfur. The impact of anion intercalation on the graphite and anion can be observed in the XPS analyses performed on the HOPG electrodes stopped at full charge and discharge conditions. 


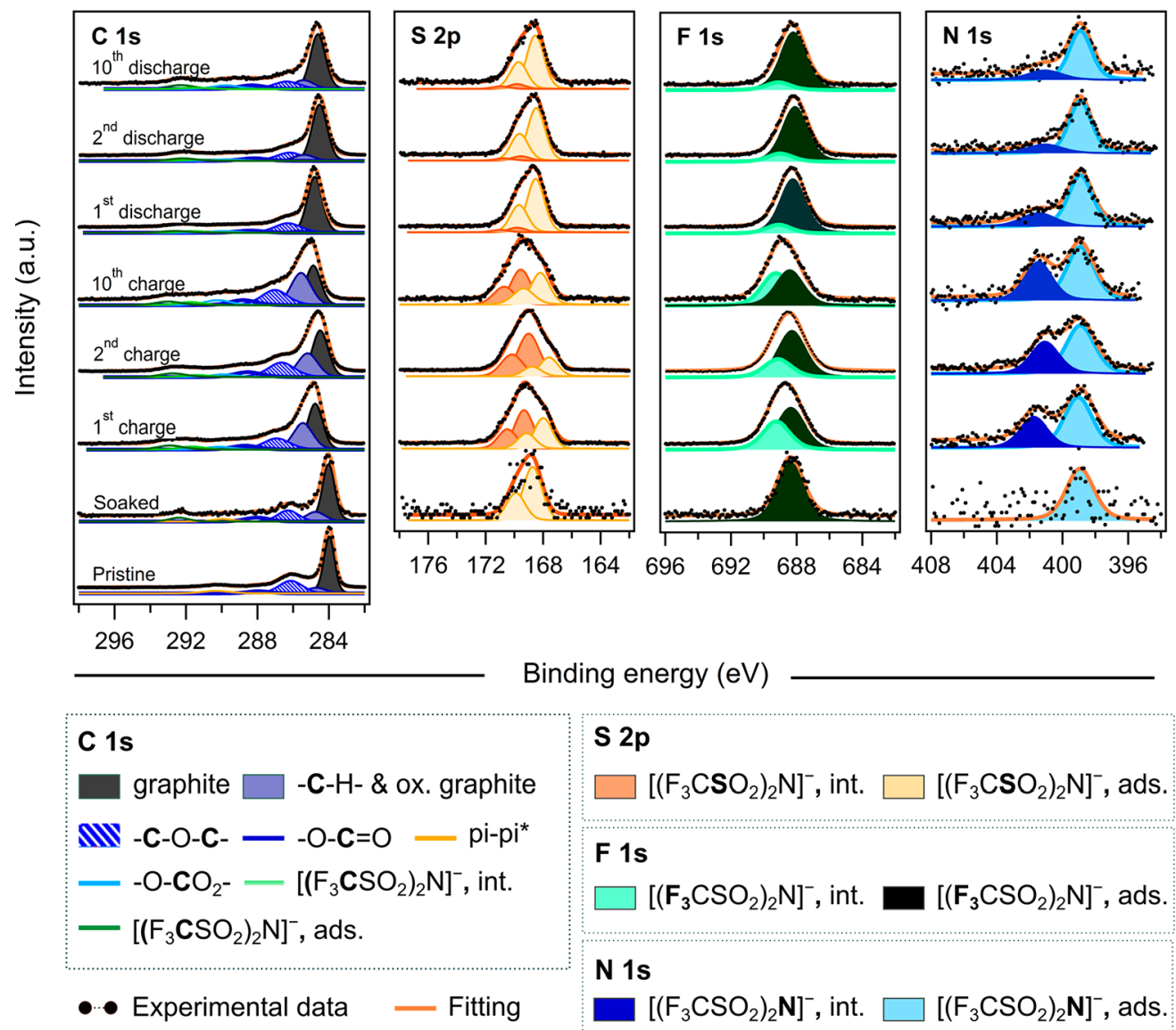

Figure 4. C 1s, S 2p, F 1s, and N 1s core level spectra of positive graphite electrodes cycled in 4 M LiTFSI in EC/DEC. The spectra of pristine,

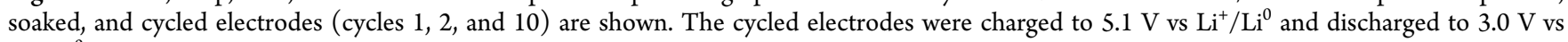
$\mathrm{Li}^{+} / \mathrm{Li}^{0}$.

Upon charging to $5.1 \mathrm{~V}$ vs $\mathrm{Li}^{+} / \mathrm{Li}^{0}$, additional peaks emerged in all the spectra and shifts in binding energies were observed. The spectra of the cycled samples were energy-calibrated by aligning the $\mathrm{N}$ 1s peak from the FSI anion in nongrounded, surface salt residues to that of the sample at OCV (at 399.1 $\mathrm{eV}$ ). With this calibration, the main graphite peak shifted to $\sim 284.8 \mathrm{eV}$, an upshift of $0.8 \mathrm{eV}$ as compared to pristine HOPG. Most importantly, a new peak emerged around 286.0 $\mathrm{eV}$ which could likely suggest the formation of $(\mathrm{FSI})_{x} \mathrm{C}_{6}$ intercalation compound in which the anion nitrogen strongly interacts with the graphite framework. Furthermore, the anion intercalation led to significant peak shifts in the $\mathrm{N} 1 \mathrm{~s}, \mathrm{~F} 1 \mathrm{~s}, \mathrm{O}$ 1s, and S 2p spectra shown in Figure 3a.

The peak shifts indicated the presence of FSI in two distinct chemical environments. The low BE peaks are thought to correspond to surface-adsorbed FSI anions and the high BE peaks to intercalated, bulk anions. As expected in such a scenario, larger shifts were observed in the nitrogen peak positions compared to the rest of the elements. A $2.91 \mathrm{eV}$ difference between the $\mathrm{N}$ 1s peaks from the adsorbed and the intercalated FSI molecules, as opposed to a shift of only 1.41 $\mathrm{eV}$ for $\mathrm{S} 2 \mathrm{p}$ and $\mathrm{F} 1 \mathrm{~s}$, suggested that the imide nitrogen interacted more strongly with the graphite framework. This was likely due to the fact that the imide nitrogen could readily donate electrons to the oxidized $\pi$-bonding orbitals of graphite. These assumptions were further supported by XPS analyses of $\mathrm{Al}$ current collectors cycled in $4 \mathrm{M} \mathrm{LiFSI}$ in EC/DEC and $4 \mathrm{M}$ LiTFSI in EC/DEC electrolytes. No new peaks were observed (see Figures S30 and S31), indicating that the additional peaks did not arise from anion decomposition, but were rather intrinsic of the anion-intercalated HOPG. After discharge to $3.0 \mathrm{~V}$ vs $\mathrm{Li}^{+} / \mathrm{Li}^{0}$ (FSI deintercalation), the peaks assigned to the intercalated FSI species ( N 1s: $401.4 \mathrm{eV}, \mathrm{S} 2 \mathrm{p}: 169.8 \mathrm{eV}$, and F 1s: $687.8 \mathrm{eV}$ ) slightly decreased in intensity. A similar effect was observed for the graphite peak assigned to the $(\mathrm{FSI})_{x} \mathrm{C}_{6}$ phase at $286.0 \mathrm{eV}$. The facts that these peaks persisted even at the discharged state and that the $\mathrm{CE}$ was only $38 \%$ (Figure S28) proved that the anions could not be fully removed from HOPG in the used voltage range, as reported in previous studies. ${ }^{40-42}$ These key findings from the HOPG study provided essential reference data for the XPS investigation of composite graphite electrodes presented in the following section.

3.2.2. CEI in Composite Graphite Electrodes. The composite graphite electrodes commonly used in dual-ion batteries consist of carbon black additives and binders. Such electrodes were electrochemically cycled to track changes in the spectra of the graphite active material in the course of anion intercalation and removal for cycles 1,2 , and 10 . The formation and chemical nature of the CEI in different electrolytes were investigated by analyzing the $\mathrm{C} 1 \mathrm{~s}, \mathrm{~F} 1 \mathrm{~s}, \mathrm{~N}$ $1 \mathrm{~s}, \mathrm{O} 1 \mathrm{~s}, \mathrm{P} 2 \mathrm{p}$, and $\mathrm{S} 2 \mathrm{p}$ spectra.

3.2.2.1. $4 \mathrm{M}$ LiTFSI in EC/DEC. The most intense peak in the pristine $\mathrm{C}$ 1s spectra (Figure 4) was attributed to $\mathrm{sp}^{2}$ hybridized carbons in graphite $(284.0 \mathrm{eV})$, while the $-\mathrm{CH}_{2}-$ $(284.6 \mathrm{eV}),-\mathrm{C}-\mathrm{O}-\mathrm{C}-(286.0 \mathrm{eV})$, and $-\mathrm{O}-\mathrm{C}=\mathrm{O}(288.0$ 

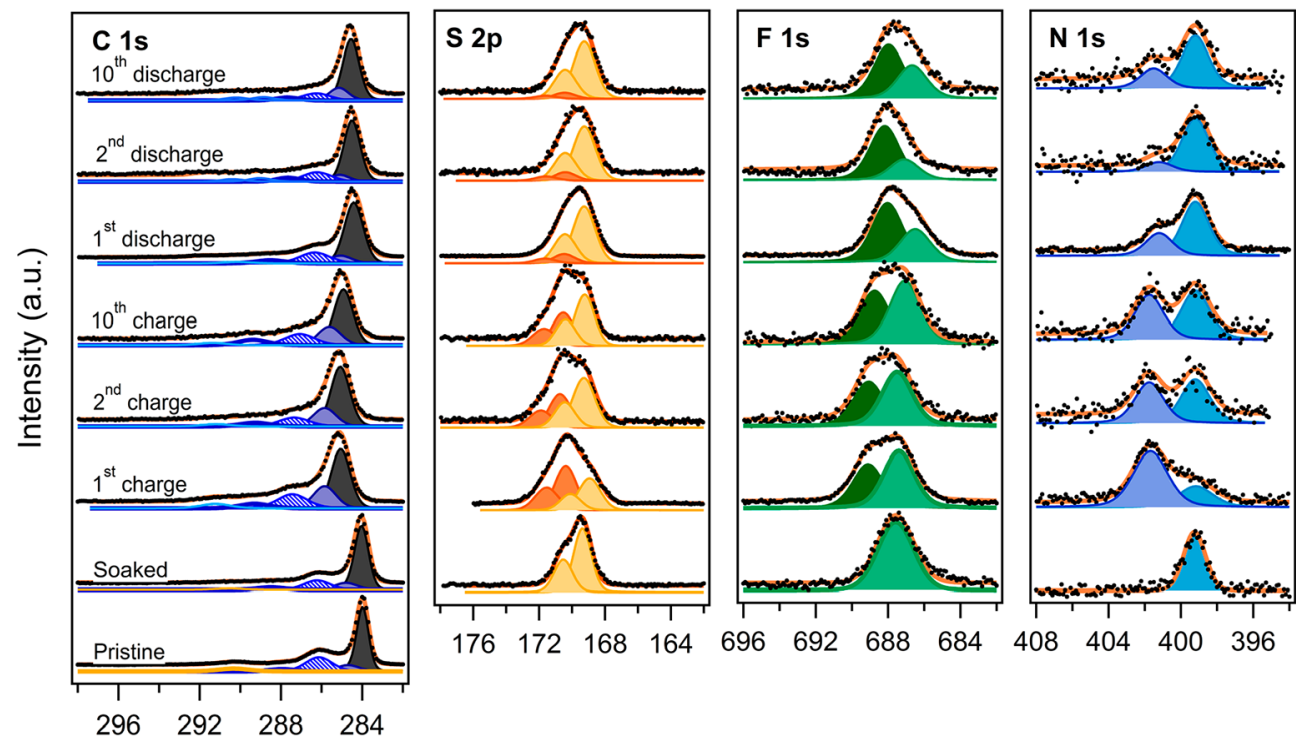

Binding energy (eV)

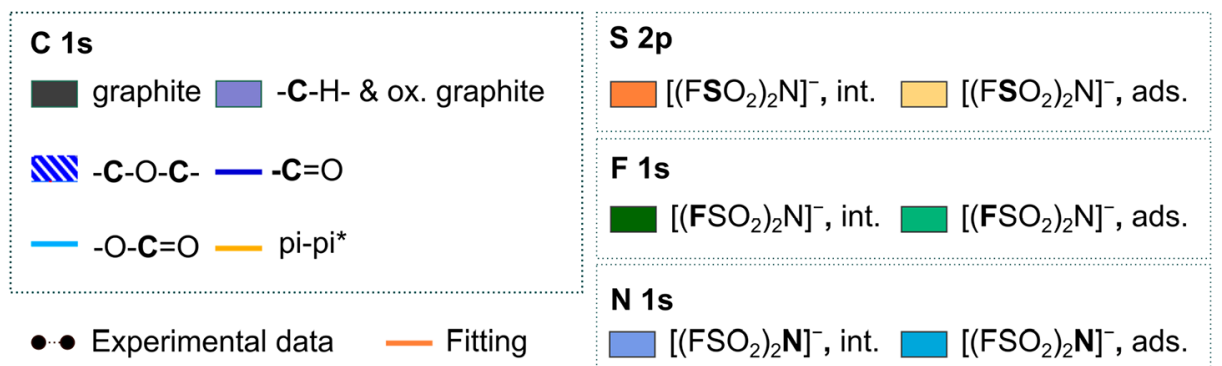

Figure 5. Surface analyses of pristine, soaked and cycled graphite electrodes: The C 1s, S 2p, F 1s, and N 1s core level spectra of positive graphite electrodes cycled in $4 \mathrm{M}$ LiFSI in EC/DEC were used to study the formation and stability of the CEI during cycles 1,2 , and 10 . The electrodes were charged to $4.95 \mathrm{~V}$ vs $\mathrm{Li}^{+} / \mathrm{Li}^{0}$ and discharged to $3.0 \mathrm{~V} \mathrm{vs} \mathrm{Li}^{+} / \mathrm{Li}^{0}$ prior to XPS study.

$\mathrm{eV}$ ) peaks originated from the carbon black additive and CMC binder. In the soaked and cycled electrodes, additional peaks appeared at $\sim 292.3 \mathrm{eV}$ due to the $-\mathrm{CF}_{3}$ group of the TFSI anion.

In the $\mathrm{C} 1 \mathrm{~s}$ spectrum, the peak around $\sim 286.0 \mathrm{eV}$ increased considerably in intensity as a result of anion intercalation in graphite electrodes charged to $5.1 \mathrm{~V}$. As observed in the HOPG study as well, the $\mathrm{sp}^{2}$-carbon peak shifted to $284.7 \mathrm{eV}$, and a new peak correlated to the formation of $\mathrm{C}-\mathrm{N}$ bonds emerged around $286 \mathrm{eV}$. Similar changes were observed in the spectra of the electrodes charged during cycles 1,2 , and 10 . No other new peaks were observed, in contrast to the solid electrolyte interphase (SEI) layer formed on negative graphite electrodes in lithium-ion batteries (LIB) in which both organic and inorganic carbonates are formed due to electrolyte decomposition. The spectra of the electrodes discharged to $3.0 \mathrm{~V}$ to remove intercalated anions bore a close similarity to the pristine and soaked electrodes. The intensity of the peak around $286 \mathrm{eV}$ diminished significantly, as the anions were deintercalated from graphite. This confirmed the high reversibility of anion intercalation in the KS6 graphite particles and the fact that the peak was indicative of the strong aniongraphite interaction in the formed intercalation compound. More importantly, both the survey (Figure S39) and C 1s corelevel spectra (Figure 4) showed that the $\mathrm{sp}^{2}$-carbon peak of graphite remained the most intense during cycling, which indicated that no substantial electrode-electrolyte interphase layer formed on the graphite particles even after 10 cycles. This could also account for the fact that intercalated anions in the graphite bulk were detected during XPS analyses. Though the absence of a thick interphase could favor the intercalation kinetics, the CE remained lower than $97 \%$ over extended cycling (Figure 2f).

Similar to what was observed for HOPG electrodes, the $S$ $2 \mathrm{p}, \mathrm{F} 1 \mathrm{~s}$ and $\mathrm{N}$ 1s spectra split into two sets of peaks upon anion intercalation at $5.1 \mathrm{~V}$ (Figure 4 ). In the $\mathrm{S} 2 \mathrm{p}$ spectra, the $\mathrm{S} 2 \mathrm{p}_{3 / 2}$ and $\mathrm{S} 2 \mathrm{p}_{1 / 2}$ doublet of the low BE peak appeared at 168.43 and $169.59 \mathrm{eV}( \pm 0.30 \mathrm{eV})$. The doublets of the high $\mathrm{BE}$ peak were located around 169.68 and $170.84 \mathrm{eV}( \pm 0.25$ $\mathrm{eV})$. The peak-to-peak difference between the $\mathrm{S} 2 \mathrm{p}_{3 / 2}$ components of the two doublets was $1.25 \pm 0.11 \mathrm{eV}$. The largest chemical shift was observed in the $\mathrm{N} 1 \mathrm{~s}$ spectra. Upon full charge to $5.1 \mathrm{~V}$, a new pair of doublets appeared at about $398.91 \mathrm{eV}$ and $401.29 \pm 0.25 \mathrm{eV}$, with a $2.37 \pm 0.25 \mathrm{eV}$ difference. As pointed out above, the additional peaks indicated the formation of rather localized $\mathrm{C}-\mathrm{N}$ bonds in the graphite intercalation compound. As expected, the peak shift in the F 1s spectra was relatively smaller $(0.87 \pm 0.02 \mathrm{eV})$, with the low and high BE peaks located at $688.27 \pm 0.11 \mathrm{eV}$ and $689.14 \pm 0.10 \mathrm{eV}$, respectively. The fluorine atoms in the $-\mathrm{CF}_{3}$ group were affected less by the oxidizing nature of the anion-intercalated graphite. The formation of the intercalation compound was highly reversible, as the peaks belonging to intercalated TFSI (at higher BEs) nearly disappeared upon 

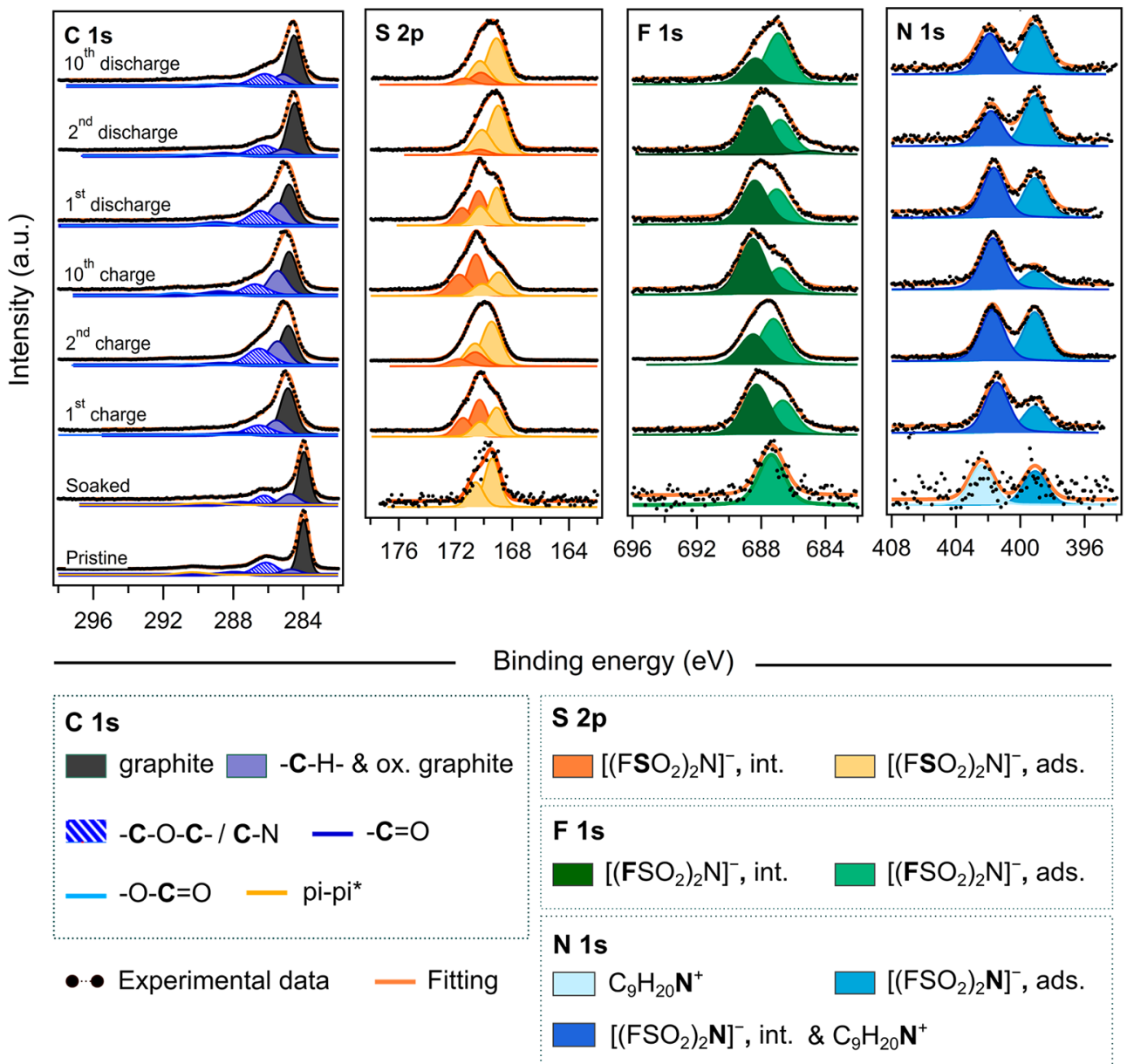

Figure 6. XPS surface analyses of graphite electrodes before and after electrochemical anion intercalation and deintercalation cycles. The spectra of pristine, soaked, and cycled electrodes (cycles 1,2, and 10) are shown. The cycled electrodes were charged to $5.1 \mathrm{Vvs} \mathrm{Li}^{+} / \mathrm{Li}^{0}$ and discharged to 3.0 $\mathrm{V}_{\mathrm{vs} \mathrm{Li}^{+}} / \mathrm{Li}^{0}$ prior to XPS study. The C $1 \mathrm{~s}, \mathrm{~S} 2 \mathrm{p}, \mathrm{F} 1 \mathrm{~s}$, and $\mathrm{N}$ 1s core level spectra of positive graphite electrodes cycled in $1 \mathrm{M} \mathrm{LiFSI} \mathrm{in} \mathrm{Pyr}{ }_{14} \mathrm{FSI}$ were used to understand the nature of the CEI.

discharge. The residual intensity corresponds to a certain amount of anions remaining trapped, either within the graphite bulk or bonded to the edge defects.

3.2.2.2. $4 \mathrm{M}$ LiFSI in EC/DEC. XPS surface analyses of the composite electrodes cycled in $4 \mathrm{M} \mathrm{LiFSI}$ in EC/DEC exhibited interface characteristics essentially similar to those of the electrodes in $4 \mathrm{M}$ LiTFSI in EC/DEC electrolyte (Figures 5 and S37). FSI intercalation and deintercalation was confirmed by the intensity changes of the $C 1$ s peak at $\sim 286.0 \mathrm{eV}$, as well as emergence of new peaks in the $\mathrm{S} 2 \mathrm{p}, \mathrm{F}$ $1 \mathrm{~s}$, and $\mathrm{N} 1 \mathrm{~s}$ peaks at higher BE. In the $\mathrm{S} 2 \mathrm{p}$ spectra, a pair of doublets appeared at $169.20 \mathrm{eV}\left(2 \mathrm{p}_{3 / 2}\right)$ for the low BE peak and at $170.50 \mathrm{eV}\left(2 \mathrm{p}_{3 / 2}\right)$ for the high $\mathrm{BE}$ peak, which resulted in an average energy difference of $1.29 \pm 0.13 \mathrm{eV}$. With regard to the $\mathrm{N}$ 1s spectra, the low BE peak was set to $399.20 \mathrm{eV}$, while the high $\mathrm{BE}$ peak appeared at $401.52 \pm 0.26 \mathrm{eV}$, leading to a $2.32 \pm 0.26 \mathrm{eV}$ difference. Removal of the anions during discharge to $3.0 \mathrm{~V}$ resulted in the disappearance of the new peaks and in the graphite $\mathrm{C} 1 \mathrm{~s}$ peak shifting to lower BE. These observations held true for all electrodes after cycles 1, 2, and 10 , and conclusively demonstrated that the intercalation process was reversible even though no permanent CEI layer formed on the electrodes. The absence of a stable passivation layer at the interface was manifested in the poor CE of FSI anion cycling in graphite, which was approximately $90 \%$ over 50 cycles as shown in Figure $2 \mathrm{f}$.

3.2.2.3. $1 \mathrm{M} \mathrm{LiFSI}$ in $\mathrm{Pyr}_{14} \mathrm{FSI}$. The electrodes cycled in the ionic liquid electrolyte showed similar XPS characteristics (Figure 6) to those electrodes cycled in the concentrated sulfonimide electrolytes. In the $\mathrm{S} 2 \mathrm{p}$ spectra, the low $\mathrm{BE}$ doublet appeared at $169.13 \mathrm{eV}\left(2 \mathrm{p}_{3 / 2}\right)$ and the high $\mathrm{BE}$ doublet at $170.40 \mathrm{eV}\left(2 \mathrm{p}_{3 / 2}\right)$, leading to a difference of $1.28 \pm$ $0.17 \mathrm{eV}$. As observed for the FSI-intercalated graphite electrodes in $4 \mathrm{M} \mathrm{LiFSI}$ in EC/DEC, two peaks were detected in the $\mathrm{F} 1 \mathrm{~s}$ spectra, around $686.87 \pm 0.44 \mathrm{eV}$ and $688.33 \pm$ $0.44 \mathrm{eV}$, leading to a separation of $1.46 \pm 0.23 \mathrm{eV}$. The energy separation between the $\mathrm{F} 1 \mathrm{~s}$ peaks suggested that the anions interact differently with graphite, as this was much smaller for TFSI $(0.87 \pm 0.02 \mathrm{eV})$. In addition, it should be noted that the high $\mathrm{BE}$ peak assigned to $\mathrm{F}$ in the intercalated species did not seem to decrease in intensity relative to the nonintercalated species upon discharge, which could in addition be indicative of the partial breakdown of the S-F bond at high operating voltages. ${ }^{43,44}$ However, the exact nature of the excess fluorine detected has not been identified here. As discussed above, BE difference between the two peaks in the $\mathrm{N}$ 1s spectra was 2.61 $\pm 0.16 \mathrm{eV}$ (peaks at $399.10 \mathrm{eV}$ and $401.71 \pm 0.16 \mathrm{eV}$ ), whereas no intensity decrease was observed in the high $\mathrm{BE}$ peaks upon discharge. Both of these phenomena could be 

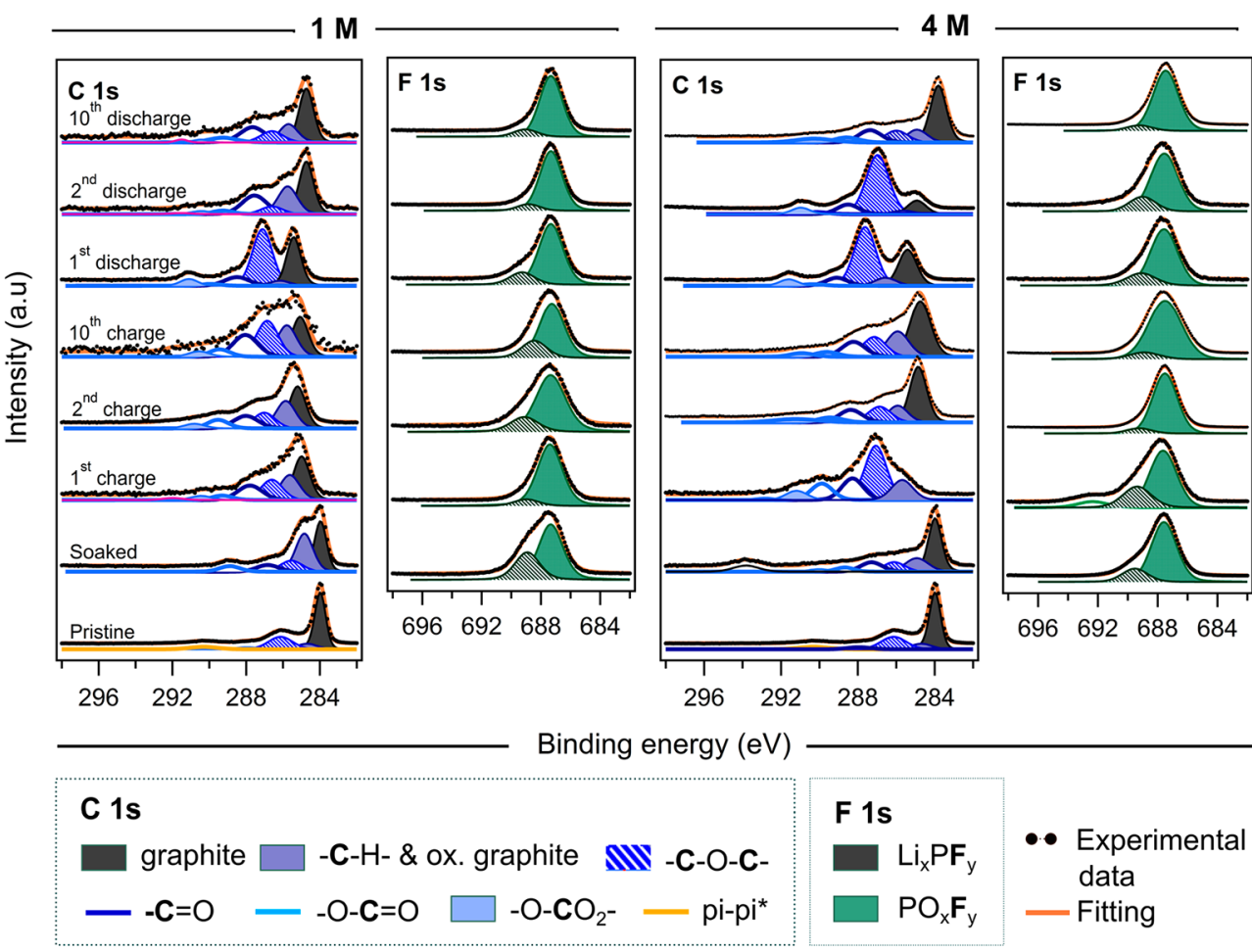

Figure 7. Nature and evolution of the electrode-electrolyte interface on positive graphite electrodes during cycles 1,2 , and 10 . The spectra of the pristine, soaked, and cycled graphite electrodes are shown. The cycled electrodes were charged to $5.1 \mathrm{Vvs} \mathrm{Li}^{+} / \mathrm{Li}^{0}$ and discharged to $3.0 \mathrm{~V}$ vs $\mathrm{Li}^{+} /$ $\mathrm{Li}^{0}$ prior to XPS study. The $\mathrm{C}$ 1s and $\mathrm{F} 1 \mathrm{~s}$ core level spectra of positive graphite electrodes cycled in $1 \mathrm{M} \mathrm{LiPF}_{6}$ in EC/DEC (a) and in $4 \mathrm{M} \mathrm{LiPF}_{6}$ in EC/DEC (b) indicated the formation of surface film composed of decomposition products from the electrolyte.

attributed to surface residues of the $\mathrm{Pyr}_{14}{ }^{+}$cation, which has a positively charged nitrogen with a $\mathrm{BE}$ around $402.5 \mathrm{eV}$.

Ideally, similar changes and trends (as in the N 1s, S 2p, and F 1s spectra) should be expected in the $\mathrm{O} 1 \mathrm{~s}$ spectra (for all of the electrolytes based on sulfonimide anions), as confirmed by XPS analyses on the HOPG electrodes. Nonetheless, in the case of the composite electrodes, there were several other oxygen-containing species (solvent, binder, and conducting additive), which would complicate the spectral interpretation. The O 1s spectra are provided as Figure S33. Finally, the Li 1s spectra for these electrolytes are also provided in Figure S32, where it is shown that principally no $\mathrm{Li}$ was detected on the surface of the graphite electrodes.

3.2.2.4. $1 \mathrm{M}$ and $4 \mathrm{MLiPF}_{6}$ in EC/DEC. As discussed earlier and shown in the SEM images (Figure S14), the graphite particles cycled in both 1 and $4 \mathrm{M} \mathrm{LiPF}_{6}$ electrolytes had a thick layer of decomposition products on the surface. In contrast to the sulfonimide electrolytes, a CEI layer was formed during cycling. In the spectra of the soaked electrodes, peaks assigned to $-\mathrm{CH}_{2}-(284.8 \mathrm{eV}),-\mathrm{C}-\mathrm{O}-\mathrm{C}-(286.0$ $\mathrm{eV})$, and $-\mathrm{O}-\mathrm{C}=\mathrm{O}(287.0-288.0 \mathrm{eV})$ functional groups were observed. Furthermore, a less intense signal was detected at a binding energy of $289.0-290.0 \mathrm{eV}$ corresponding to $-\mathrm{O}-$ $\mathrm{CO}_{2}-$ groups. Upon charging, the peaks increased in intensity due to accumulation of polyethers, and polycarbonates originating from the oxidative decomposition of EC. Although theoretical studies recognize EC as being relatively inert toward oxidative degradation (up to $5.5 \mathrm{~V}$ vs $\mathrm{Li}^{+} / \mathrm{Li}^{0}$ ), its stability can be altered significantly in the presence fluorinated anions. ${ }^{45}$ The decomposition of EC on the negative electrode usually involves ring opening and dimerization leading to the formation of diverse alkyl carbonates, e.g., $\left(\mathrm{CH}_{2} \mathrm{OCO}_{2} \mathrm{Li}\right)_{2}$.
The generation of similar reaction products on the positive electrode is highly probable and has been observed for transition metal oxide cathodes operating above $4.0 \mathrm{~V}$ vs $\mathrm{Li}^{+}$/ $\mathrm{Li}^{0}{ }^{46}$ Here, it appears as if the higher salt concentration has, instead of leading to improved electrolyte stability, induced further decomposition.

Apart from EC, the salt gave rise to additional decomposition products as confirmed in the survey (Figures S40 and S41) and in the F 1s spectra of the $\mathrm{LiPF}_{6}$ systems (Figure 7). The $\mathrm{F} 1 \mathrm{~s}$ peak was particularly intense, suggesting that the CEI is rich in fluorine-containing compounds, possibly $\mathrm{Li}_{x} \mathrm{PF}_{y}$ $(\sim 689.0 \mathrm{eV})$ and $\mathrm{PO}_{x} \mathrm{~F}_{y}(\sim 687.3 \mathrm{eV})$. Further evidence for the existence of these species can be seen in the Li 1s (Figure S34) and P 2p (Figure S35) spectra. The presence of Li in the CEI was confirmed by a broad peak at $57.5 \mathrm{eV}$. The maximum of the P $2 \mathrm{p}$ doublet appears at approximately $136.3 \mathrm{eV}$ for the OCV sample, which is in good agreement with the literature value for phosphorus in $\mathrm{PF}_{6}^{-}$and $\mathrm{PF}_{x}^{-}(x \leq 5)$. After anion cycling in the graphite electrodes, the $\mathrm{P} 2 \mathrm{p}$ peak at the lower $\mathrm{BE}(\sim 135.0 \mathrm{eV})$ increased in intensity, which is in agreement with the increase in the $\mathrm{PO}_{x} \mathrm{~F}_{y}$ species.

Notably, in the case of $\mathrm{LiPF}_{6}$-based electrolytes, the peaks due to anion intercalation could not be observed clearly in any of the spectra as a result of the high amount of decomposition products covering the electrode surface. As mentioned earlier, electrolytes based on $\mathrm{LiPF}_{6}$ have shown the ability to form solid electrolyte interphases rich in inorganic compounds such as $\mathrm{LiF}, \mathrm{LiPF}_{x}$, and $\mathrm{LiPF}_{x} \mathrm{O}_{y}$ as well as organic decomposition products, owing to the partial hydrolysis of the $\mathrm{PF}_{6}{ }^{-}$anion. The exact physicochemical properties of these interphases could vary substantially, depending on the electrode material, electrolyte formulation and cycling conditions. ${ }^{47}$ Here, severe 
electrolyte decomposition was observed over 50 cycles, resulting in a thick CEI layer and demonstrating that electrolytes combining $\mathrm{LiPF}_{6}$ (as the main salt) and EC might be unsuitable for use in GDIBs. ${ }^{37}$

The XPS findings described in this section correlated well with both electrochemical and microscopy characterizations. To summarize, three ideal cases can be envisaged regarding the nature and stability the CEI, as shown schematically in Figure $8 \mathrm{~d}$. In concentrated sulfonimide salt electrolytes, no substantial

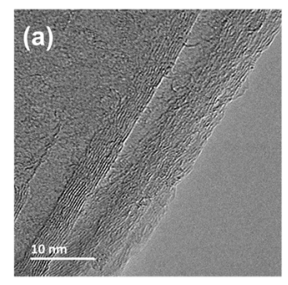

(d) Case 1: No substantial CEI

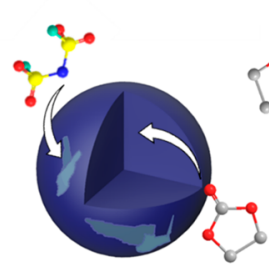

$4 M$ LiTFSI in EC:DEC $4 M$ LiFSI in EC:DEC $1 \mathrm{M}$ LiFSI in Pyr 14 FSI

Graphite particle Anion intercalant Blocking CEI Solvent species

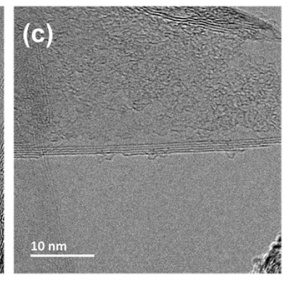

Case 3: Permeable CEI

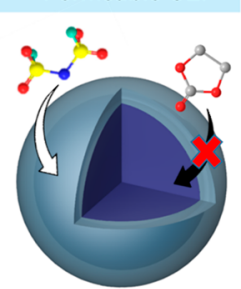

Concentrated sulfonimide-based electrolyte + additive

Permeable CEI
Figure 8. $(\mathrm{a}-\mathrm{c}) \mathrm{TEM}$ images of graphite cathodes cycled in $4 \mathrm{M}$ LiTFSI in EC/DEC, $1 \mathrm{M} \mathrm{LiFSI} \mathrm{in} \mathrm{Pyr}_{14} \mathrm{FSI}$, and in $4 \mathrm{M} \mathrm{LiFSI}$ in EC/ DEC, respectively. The absence of a distinct CEI is evident, as the graphite lattice fringes continue until the edge of the KS6 particles. (d) Schematic illustration of a graphite particle without CEI (1), with a blocking CEI (2), and with a CEI permeable to the anion intercalant (3). The third case is the most desirable, as this functional CEI allows for the insertion/deinsertion of the anion, while it blocks the solvent molecules from entering the graphite, causing side reactions and aggravated exfoliation.

CEI, apart from a thin layer of chemisorbed anions, was formed on graphite particles even after 10 cycles. Apart from XPS and SEM, these observations were verified through TEM characterization (Figures $8 \mathrm{a}-\mathrm{c}$ and S20-S23). The TEM images confirmed that no CEI resided on the graphite particles cycled in the LiFSI/LiTFSI-based HCEs and IL, as the graphite lattice fringes could be clearly seen until the flakes' outer edges. The lack of desirable interface passivation limits the CE in these electrolytes to lower than $95 \%$, and it can be safely assumed that the stabilization of the electrolyte at such extreme voltages was due to the extensive coordination of both solvent molecules and anions to $\mathrm{Li}^{+}$. Hence, a high salt concentration was imperative for a well-functioning DIB. In the second case, typical for the electrolytes based on the $\mathrm{PF}_{6}{ }^{-}$containing salts in EC, an interphase layer composed of both organic and inorganic compounds is formed as a result of the decomposition of $\mathrm{PF}_{6}{ }^{-}$anion and ethylene carbonate solvent. However, this CEI was found to grow thicker and actually impeded anion intercalation. Introducing a limited amount of
$\mathrm{LiPF}_{6}$ in the sulfonimide electrolytes could potentially lead to CEI layer formation and increase in CE as preliminary results indicated (Figure S12). This could result in an "ideal" CEI, represented by case 3 shown in the schematic, in which a thin CEI is formed, solely permeable to the anions. Nonetheless, the amount of $\mathrm{LiPF}_{6}$ additive requires optimization in order to ensure that the CEI will remain thin and anionically conductive.

\section{CONCLUSIONS}

The highly concentrated electrolytes (4 M) based on LiFSI/ LiTFSI in EC/DEC delivered a superior electrochemical performance compared to the other systems studied, in terms of anion intercalation kinetics, specific discharge capacity (86 $\mathrm{mAh} \mathrm{g}^{-1}$ for LiFSI and $102 \mathrm{mAh} \mathrm{g}^{-1}$ for LiTFSI) and CE (9095\% after 10 cycles). The $4 \mathrm{M} \mathrm{LiTFSI}$ in EC/DEC electrolyte proved stable up to $5.1 \mathrm{~V}$ vs $\mathrm{Li}^{+} / \mathrm{Li}^{0}$, while $4 \mathrm{M} \mathrm{LiFSI}$ in EC/ DEC was limited to $4.95 \mathrm{~V}$ vs $\mathrm{Li}^{+} / \mathrm{Li}^{0}$. A high salt concentration $(\geq 4 \mathrm{M})$ proved essential in order to stabilize the $\mathrm{Al}$ current collector and enable electrochemical cycling. The IL electrolyte ( $1 \mathrm{M} \mathrm{LiFSI}$ in $\mathrm{Pyr}_{14} \mathrm{FSI}$ ) exhibited a similar electrochemical stability window $\left(5.1 \mathrm{~V}\right.$ vs $\left.\mathrm{Li} / \mathrm{Li}^{+}\right)$and specific discharge capacity $\left(84 \mathrm{mAh} \mathrm{g}^{-1}\right)$. However, the IL suffered from inferior kinetics of anion intercalation and poor $\mathrm{CE}$ ( $\sim 60-70 \%)$. Electrolyte systems based on $\mathrm{LiPF}_{6}$ salt (at 1 and $4 \mathrm{M}$ concentrations) resulted in low discharge capacities ( 46-55 $\left.\mathrm{mAh}^{-1}\right)$, high intercalation overpotentials, and substantial irreversibility (CE: 20-60\%), linked to the decomposition of the $\mathrm{PF}_{6}^{-}$anion and ethylene carbonate solvent.

The electrochemistry was supported by post-mortem XPS measurements. XPS performed on HOPG cycled in $1 \mathrm{M} \mathrm{LiFSI}$ in $\mathrm{Pyr}_{14} \mathrm{FSI}$ revealed the presence of a thin CEI layer composed of adsorbed anions, through which the intercalated species could be simultaneously probed. The signals of intercalated anions appeared to shift toward higher binding energies relative to the adsorbed species. The shift was elementdependent, with $\mathrm{N}$ 1s showing the largest shift (2.9 vs $1.4 \mathrm{eV}$ for $S 2 p, F 1 s$, and $O$ 1s), which indicated a stronger interaction between the anion nitrogen and the graphite. In addition, the anion-intercalated graphite gave rise to a distinct peak, shifted $\sim 0.7 \mathrm{eV}$ to the main $\mathrm{C} 1 \mathrm{~s}$ line. XPS performed on composite graphite electrodes cycled in $4 \mathrm{M}$ LiFSI/LiTFSI in $\mathrm{EC} / \mathrm{DEC}$ and in $1 \mathrm{M}$ LiFSI-IL indicated the formation of a similar interface to that of HOPG. The absence of a conventional CEI proved that these systems are kinetically stabilized, owing to the high salt concentration. Systems cycled in $\mathrm{LiPF}_{6}$-containing electrolytes resulted instead in a thicker $\mathrm{CEI}$, rich in EC-derivatives (polyethers and polycarbonates) and decomposed salt $\left(\mathrm{Li}_{x} \mathrm{PF}_{y} / \mathrm{PO}_{x} \mathrm{~F}_{y} / \mathrm{Li}_{x} \mathrm{PO}_{y} \mathrm{~F}_{z}\right)$. Extensive breakdown occurred irrespective of the $\mathrm{LiPF}_{6}$ concentration, which indicated that these electrolyte compositions are unsuitable for GDIBs. Nonetheless, the passivating layers observed on both the $\mathrm{Al}$ current collector and graphite electrode highlighted the potential of $\mathrm{LiPF}_{6}$ as a CEI-forming additive. Using $\mathrm{LiPF}_{6}$ alongside other CEI-forming additives in concentrated sulfonimide electrolytes is the subject of an ongoing study, targeting a further increase in the stability of electrolytes tailored for graphite dual-ion batteries. 


\section{ASSOCIATED CONTENT}

\section{S) Supporting Information}

The Supporting Information is available free of charge at https://pubs.acs.org/doi/10.1021/acsami.0c18586.

Further electrochemical characterization of $\mathrm{Al}$ current collectors and graphite cathodes, SEM and EDS of cycled Al current collectors and KS6 graphite cathodes, ex situ TEM of cycled graphite cathodes, Raman spectroscopy of pristine cycled graphite cathodes, XRD of pristine cycled graphite cathodes, complementary XPS data on cycled, highly ordered pyrolytic graphite and KS6 graphite (PDF)

\section{AUTHOR INFORMATION}

\section{Corresponding Author}

Antonia Kotronia - Department of Chemistry-Ångström

Laboratory, Uppsala University, Uppsala SE-75121,

Sweden; (1) orcid.org/0000-0002-2272-4478;

Email: antonia.kotronia@kemi.uu.se

\section{Authors}

Habtom D. Asfaw - Department of Chemistry-Ångström Laboratory, Uppsala University, Uppsala SE-75121, Sweden; 10 orcid.org/0000-0001-5861-4281

Cheuk-Wai Tai - Department of Materials and Environmental Chemistry, Stockholm University, Stockholm SE-10691, Sweden; (1) orcid.org/0000-0001-7286-1211

Maria Hahlin - Department of Chemistry-Ångström Laboratory, Uppsala University, Uppsala SE-75121, Sweden

Daniel Brandell - Department of Chemistry-Ångström Laboratory, Uppsala University, Uppsala SE-75121, Sweden; (1) orcid.org/0000-0002-8019-2801

Kristina Edström - Department of Chemistry-Ångström Laboratory, Uppsala University, Uppsala SE-75121, Sweden; (1) orcid.org/0000-0003-4440-2952

Complete contact information is available at: https://pubs.acs.org/10.1021/acsami.0c18586

\section{Author Contributions}

A.K. and H.D.A. designed the project and wrote the first draft of the manuscript. A.K. performed the SEM characterizations, electrochemical testing and XPS measurements and processed the data. H.D.A. contributed to the analysis and interpretation of the electrochemical data. C.W.T. performed the TEM characterization. M.H. and K.E. participated in the design and interpretation of the XPS study. All authors contributed to the discussions of the results and the revision of the original draft of the manuscript.

\section{Notes}

The authors declare no competing financial interest.

\section{ACKNOWLEDGMENTS}

Financial support for the project was provided by the Swedish Energy Agency (2015-009549 and 2016-006026), Vetenskapsrådet (D-2017-05466), Vinnova (2019-00064), Uppsala University, and the STandUp for Energy consortium. The Myfab-LIMS (Uppsala University) and the Knut and Alice Wallenberg Foundation (Stockholm University) are acknowledged for the provision of electron microscopy facilities used to collect the SEM and TEM images, respectively.

\section{REFERENCES}

(1) Battke, B.; Schmidt, T. S.; Grosspietsch, D.; Hoffmann, V. H. A Review and Probabilistic Model of Lifecycle Costs of Stationary Batteries in Multiple Applications. Renewable Sustainable Energy Rev. 2013, 25, 240-250.

(2) Dunn, B.; Kamath, H.; Tarascon, J.-M. Electrical Energy Storage for the Grid: a Battery of Choices. Science 2011, 334 (6058), 928935.

(3) Wang, M.; Tang, Y. A Review on the Features and Progress of Dual-Ion Batteries. Adv. Energy Mater. 2018, 8 (19), 1703320.

(4) Placke, T.; Heckmann, A.; Schmuch, R.; Meister, P.; Beltrop, K.; Winter, M. Perspective on Performance, Cost, and Technical Challenges for Practical Dual-ion Batteries. Joule 2018, 2 (12), 2528-2550.

(5) Kravchyk, K. V.; Kovalenko, M. V. Rechargeable Dual-Ion Batteries with Graphite as a Cathode: Key Challenges and Opportunities. Adv. Energy Mater. 2019, 9 (35), 1901749.

(6) Dahn, J. R.; Seel, J. A. Energy and Capacity Projections for Practical Dual-Graphite Cells. J. Electrochem. Soc. 2000, 147 (3), 899.

(7) Wang, M.; Tang, Y. A Review on the Features and Progress of Dual-Ion Batteries. Adv. Energy Mater. 2018, 8 (19), 1703320.

(8) Heckmann, A.; Thienenkamp, J.; Beltrop, K.; Winter, M.; Brunklaus, G.; Placke, T. Towards High-performance Dual-graphite Batteries Using Highly Concentrated Organic Electrolytes. Electrochim. Acta 2018, 260, 514-525.

(9) Miyoshi, S.; Nagano, H.; Fukuda, T.; Kurihara, T.; Watanabe, M.; Ida, S.; Ishihara, T. Dual-carbon Battery Using High Concentration LiPF6 in Dimethyl Carbonate (DMC) Electrolyte. J. Electrochem. Soc. 2016, 163 (7), A1206-A1213.

(10) Kravchyk, K. V.; Bhauriyal, P.; Piveteau, L.; Guntlin, C. P.; Pathak, B.; Kovalenko, M. V. High-energy-density Dual-ion Battery for Stationary Storage of Electricity Using Concentrated Potassium Fluorosulfonylimide. Nat. Commun. 2018, 9 (1), 4469.

(11) McCullough, F.; Levine, C.; Snelgrove, R. Secondary Battery. US4,830,938A, 1989.

(12) Jiang, X.; Luo, L.; Zhong, F.; Feng, X.; Chen, W.; Ai, X.; Yang, H.; Cao, Y. Electrolytes for Dual-Carbon Batteries. ChemElectroChem 2019, 6 (10), 2615-2629.

(13) Mai, S.; Xu, M.; Liao, X.; Hu, J.; Lin, H.; Xing, L.; Liao, Y.; Li, X.; Li, W. Tris (trimethylsilyl) phosphite as Electrolyte Additive for High Voltage Layered Lithium Nickel Cobalt Manganese Oxide Cathode of Lithium Ion Battery. Electrochim. Acta 2014, 147, 565571.

(14) Placke, T.; Schmuelling, G.; Kloepsch, R.; Meister, P.; Fromm, O.; Hilbig, P.; Meyer, H.-W.; Winter, M. In situ X-ray Diffraction Studies of Cation and Anion Intercalation into Graphitic Carbons for Electrochemical Energy Storage Applications. Z. Anorg. Allg. Chem. 2014, 640 (10), 1996-2006.

(15) Ma, T.; Xu, G.-L.; Li, Y.; Wang, L.; He, X.; Zheng, J.; Liu, J.; Engelhard, M. H.; Zapol, P.; Curtiss, L. A.; et al. Revisiting the Corrosion of the Aluminum Current Collector in Lithium-ion Batteries. J. Phys. Chem. Lett. 2017, 8 (5), 1072-1077.

(16) Beltrop, K.; Meister, P.; Klein, S.; Heckmann, A.; Gruenebaum, M.; Wiemhöfer, H.-D.; Winter, M.; Placke, T. Does Size Really Matter? New Insights into the Intercalation Behavior of Anions into a Graphite-based Positive Electrode for Dual-ion Batteries. Electrochim. Acta 2016, 209, 44-55.

(17) Meister, P.; Siozios, V.; Reiter, J.; Klamor, S.; Rothermel, S.; Fromm, O.; Meyer, H.-W.; Winter, M.; Placke, T. Dual-ion Cells Based on the Electrochemical Intercalation of Asymmetric Fluorosulfonyl-(trifluoromethanesulfonyl)imide Anions into Graphite. Electrochim. Acta 2014, 130, 625-633.

(18) Read, J. A. In-Situ Studies on the Electrochemical Intercalation of Hexafluorophosphate Anion in Graphite with Selective Cointercalation of Solvent. J. Phys. Chem. C 2015, 119 (16), 8438-8446.

(19) Zhang, X.; Tang, Y.; Zhang, F.; Lee, C.-S. A Novel AluminumGraphite Dual-Ion Battery. Adv. Energy Mater. 2016, 6 (11), 1502588.

(20) Beltrop, K.; Qi, X.; Hering, T.; Röser, S.; Winter, M.; Placke, T. Enabling Bis(fluorosulfonyl)imide-based Ionic Liquid Electrolytes for 
Application in Dual-ion Batteries. J. Power Sources 2018, 373, 193202.

(21) Read, J. A.; Cresce, A. V.; Ervin, M. H.; Xu, K. Dual-graphite Chemistry Enabled by a High Voltage Electrolyte. Energy Environ. Sci. 2014, 7 (2), 617-620.

(22) Märkle, W.; Tran, N.; Goers, D.; Spahr, M. E.; Novák, P. The Influence of Electrolyte and Graphite Type on the PF6- Intercalation Behaviour at High Potentials. Carbon 2009, 47 (11), 2727-2732.

(23) Placke, T.; Rothermel, S.; Fromm, O.; Meister, P.; Lux, S. F.; Huesker, J.; Meyer, H.-W.; Winter, M. Influence of Graphite Characteristics on the Electrochemical Intercalation of Bis (trifluoromethanesulfonyl)imide Anions into a Graphite-based Cathode. J. Electrochem. Soc. 2013, 160 (11), A1979.

(24) Heckmann, A.; Fromm, O.; Rodehorst, U.; Münster, P.; Winter, M.; Placke, T. New Insights into Electrochemical Anion Intercalation into Carbonaceous Materials for Dual-ion Batteries: Impact of the Graphitization Degree. Carbon 2018, 131, 201-212.

(25) Edström, K.; Gustafsson, T.; Thomas, J. O. The Cathodeelectrolyte Interface in the Li-ion Battery. Electrochim. Acta 2004, 50 (2), 397-403.

(26) Kim, J.-H.; Pieczonka, N. P. W.; Yang, L. Challenges and Approaches for High-Voltage Spinel Lithium-Ion Batteries. ChemPhysChem 2014, 15 (10), 1940-1954.

(27) Li, W.-H.; Ning, Q.-L.; Xi, X.-T.; Hou, B.-H.; Guo, J.-Z.; Yang, Y.; Chen, B.; Wu, X.-L. Highly Improved Cycling Stability of Anion De-/Intercalation in the Graphite Cathode for Dual-Ion Batteries. Adv. Mater. 2019, 31 (4), 1804766.

(28) Marom, R.; Amalraj, S. F.; Leifer, N.; Jacob, D.; Aurbach, D. A Review of Advanced and Practical Lithium Battery Materials. J. Mater. Chem. 2011, 21 (27), 9938-9954.

(29) Myung, S.-T.; Hitoshi, Y.; Sun, Y.-K. Electrochemical Behavior and Passivation of Current Collectors in Lithium-ion Batteries. J. Mater. Chem. 2011, 21 (27), 9891-9911.

(30) Yang, H.; Zhuang, G. V.; Ross, P. N., Jr Thermal Stability of LiPF6 Salt and Li-ion Battery Electrolytes Containing LiPF6. J. Power Sources 2006, 161 (1), 573-579.

(31) Han, H.-B.; Zhou, S.-S.; Zhang, D.-J.; Feng, S.-W.; Li, L.-F.; Liu, K.; Feng, W.-F.; Nie, J.; Li, H.; Huang, X.-J. Lithium Bis(fluorosulfonyl)imide (LiFSI) as Conducting Salt for Nonaqueous Liquid Electrolytes for Lithium-ion Batteries: Physicochemical and Electrochemical Properties. J. Power Sources 2011, 196 (7), 36233632.

(32) Kühnel, R.-S.; Balducci, A. Comparison of the Anodic Behavior of Aluminum Current Collectors in Imide-based Ionic Liquids and Consequences on the Stability of High Voltage Supercapacitors. J. Power Sources 2014, 249, 163-171.

(33) Wang, X.; Yasukawa, E.; Mori, S. Inhibition of Anodic Corrosion of Aluminum Cathode Current Collector on Recharging in Lithium Imide Electrolytes. Electrochim. Acta 2000, 45 (17), 26772684.

(34) Yamada, Y.; Chiang, C. H.; Sodeyama, K.; Wang, J.; Tateyama, Y.; Yamada, A. Corrosion Prevention Mechanism of Aluminum Metal in Superconcentrated Electrolytes. ChemElectroChem 2015, 2 (11), $1687-1694$

(35) Matsumoto, K.; Inoue, K.; Nakahara, K.; Yuge, R.; Noguchi, T.; Utsugi, K. Suppression of Aluminum Corrosion by Using High Concentration LiTFSI Electrolyte. J. Power Sources 2013, 231, 234238.

(36) Vetter, J.; Novák, P.; Wagner, M. R.; Veit, C.; Möller, K.-C.; Besenhard, J.; Winter, M.; Wohlfahrt-Mehrens, M.; Vogler, C.; Hammouche, A. Ageing Mechanisms in Lithium-ion Batteries. $J$. Power Sources 2005, 147 (1-2), 269-281.

(37) Zhu, Y.-R.; Yi, T.-F. Recent Progress in the Electrolytes for Improving the Cycling Stability of LiNi 0.5 Mn 1.5 O 4 High-voltage Cathode. Ionics 2016, 22 (10), 1759-1774.

(38) Jagadeesh, M. S.; Bussetti, G.; Calloni, A.; Yivlialin, R.; Brambilla, L.; Accogli, A.; Gibertini, E.; Alliata, D.; Goletti, C.; Ciccacci, F.; Magagnin, L.; Castiglioni, C.; Duò, L. Incipient Anion Intercalation of Highly Oriented Pyrolytic Graphite Close to the
Oxygen Evolution Potential: A Combined X-ray Photoemission and Raman Spectroscopy Study. J. Phys. Chem. C 2019, 123 (3), 17901797.

(39) Preibisch, Y.; Horsthemke, F.; Winter, M.; Nowak, S.; Best, A. S. Is the Cation Innocent? An Analytical Approach on the Cationic Decomposition Behavior of N-Butyl-N-methylpyrrolidinium Bis(trifluoromethanesulfonyl)imide in Contact with Lithium Metal. Chem. Mater. 2020, 32 (6), 2389-2398.

(40) Foelske-Schmitz, A.; Weingarth, D.; Kaiser, H.; Kötz, R. Quasi In Situ XPS study of Anion Intercalation into HOPG from the Ionic Liquid [EMIM][BF4]. Electrochem. Commun. 2010, 12 (10), 14531456.

(41) Foelske-Schmitz, A.; Weingarth, D.; Kötz, R. Quasi In Situ XPS Study of Electrochemical Oxidation and Reduction of Highly Oriented Pyrolytic Graphite in [1-ethyl-3-methylimidazolium][BF4] Electrolytes. Electrochim. Acta 2011, 56 (28), 10321-10331.

(42) Foelske-Schmitz, A.; Ruch, P. W.; Kötz, R. Ion Intercalation into HOPG in Supercapacitor Electrolyte - An X-ray Photoelectron Spectroscopy Study. J. Electron Spectrosc. Relat. Phenom. 2010, 182 (1), 57-62.

(43) Shkrob, I. A.; Marin, T. W.; Zhu, Y.; Abraham, D. P. Why Bis(fluorosulfonyl)imide Is a "Magic Anion" for Electrochemistry. J. Phys. Chem. C 2014, 118 (34), 19661-19671.

(44) Huang, J.; Hollenkamp, A. F. Thermal Behavior of Ionic Liquids Containing the FSI Anion and the Li+ Cation. J. Phys. Chem. C 2010, 114 (49), 21840-21847.

(45) Li, T.; Xing, L.; Li, W.; Wang, Y.; Xu, M.; Gu, F.; Hu, S. How Does Lithium Salt Anion Affect Oxidation Decomposition Reaction of Ethylene Carbonate: A density Functional Theory Study. J. Power Sources 2013, 244, 668-674.

(46) Yang, L.; Ravdel, B.; Lucht, B. L. Electrolyte Reactions with the Surface of High Voltage LiNi0. 5Mn1. $5 \mathrm{O} 4$ Cathodes for Lithium-ion Batteries. Electrochem. Solid-State Lett. 2010, 13 (8), A95-A97.

(47) Wagner, R.; Korth, M.; Streipert, B.; Kasnatscheew, J.; Gallus, D. R.; Brox, S.; Amereller, M.; Cekic-Laskovic, I.; Winter, M. Impact of Selected LiPF6 Hydrolysis Products on the High Voltage Stability of Lithium-Ion Battery Cells. ACS Appl. Mater. Interfaces 2016, 8 (45), 30871-30878. 